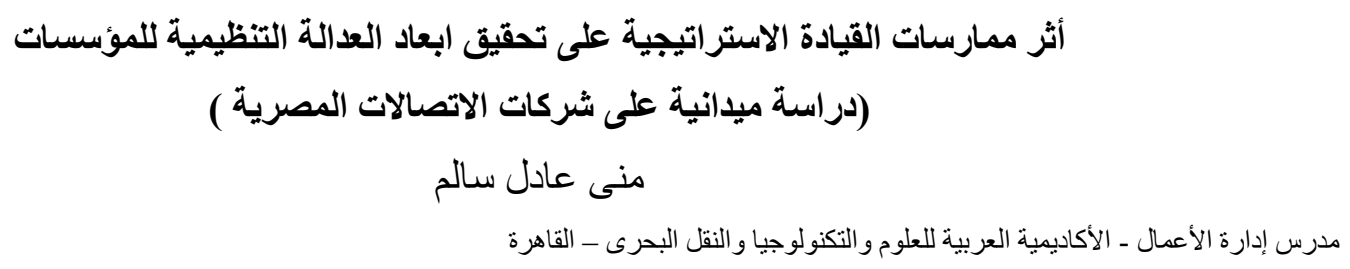

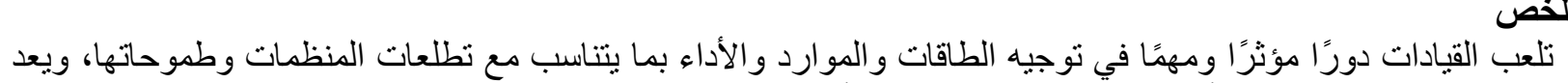

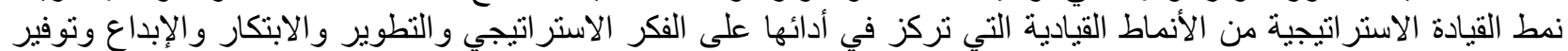

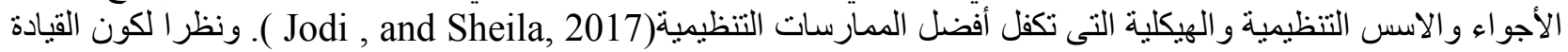

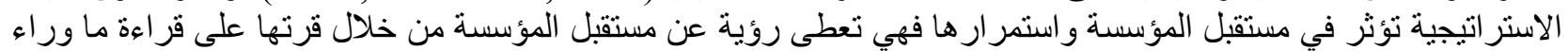

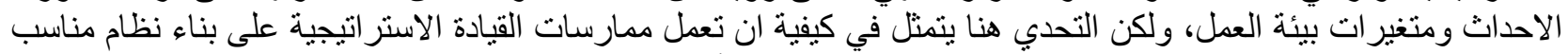

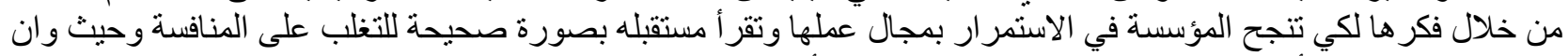

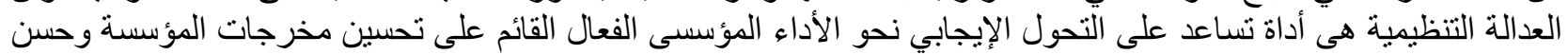

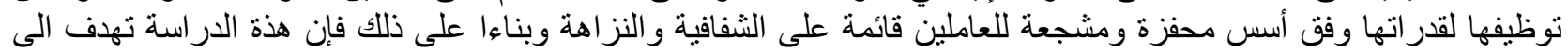

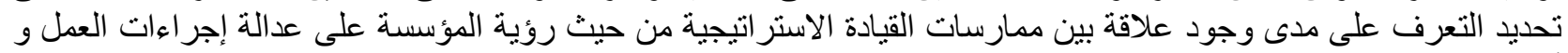

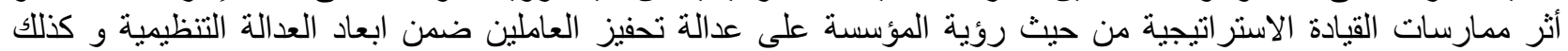

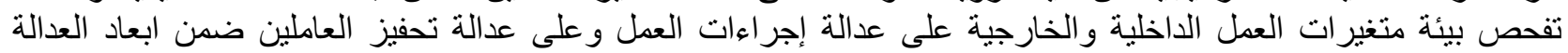

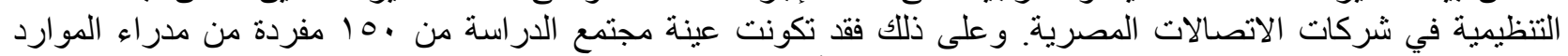

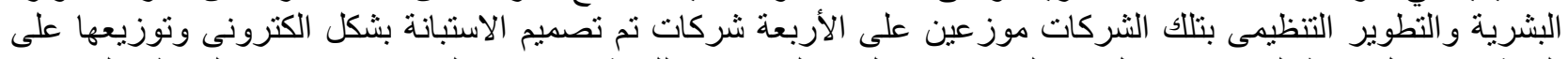

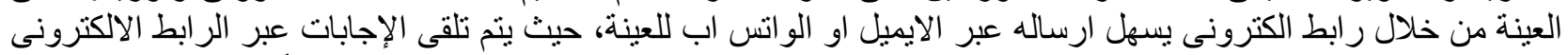

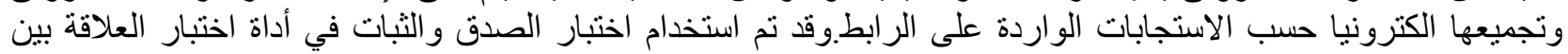

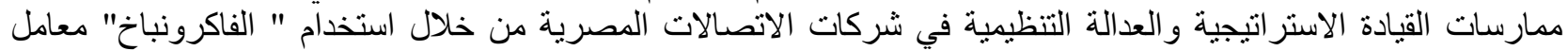

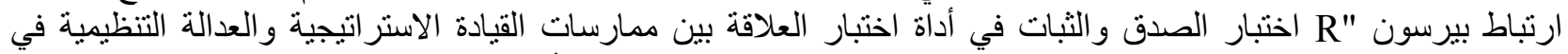
شركات الاتصالات المصرية و نموذج الانحدار الخطي البسيط لتحديد معنوية تأثثير للفرضية الرئيسية بين ممارسات التئية القيادة

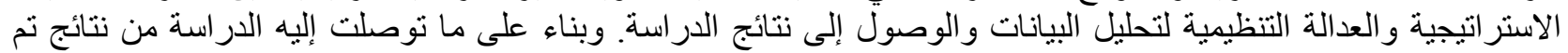
اقتر اح مجمو عة من التوصيات ، و عرض مقترحات لدر اسات مستقبلية ذات علاقة بقضية البحث.

$$
\text { كلمات دالة: ممارساتـ قيادة استر اتيجية- ابتكار - ابداع }
$$

\begin{abstract}
The strategic leadership style focuses on its performance on strategic thinking, development, innovation and creativity, and provides the organizational and structural atmosphere and foundations that ensure best organizational practices (Jodi, and Sheila, 2017). Because strategic leadership influences the organization's future and sustainability, it gives a vision of the institution's future through its reading of events and changes in the work environment But the challenge here is how strategic leadership practices work to build an appropriate system through their thinking so that the organization succeeds in continuing its field of work and correctly reading its future to overcome competition and where organizational justice is a tool for positive transformation towards effective institutional performance based on improved outcomes This study aims to identify the relationship between the strategic leadership practices in terms of the institution's vision of the fairness of the work procedures and the impact of the Arsat strategic leadership in terms of the organization's vision on justice, motivate staff within the dimensions of organizational justice The environment of internal and external business variables also examines the fairness of work procedures and the fairness of
\end{abstract}


motivating employees within the regulatory justice dimensions of Egyptian telecom companies. Thus, the sample of the study population consisted ( 150) human resource managers and organizational development of these companies distributed among the four companies. The questionnaire was designed electronically and distributed to the sample through an e-mail link which is easy to send via e-mail or sample. And was collected electronically according to the responses contained in the link. The test of honesty and consistency was used in the tool to test the relationship between the strategic leadership and regulatory justice practices in the Egyptian telecom companies through the use of the Vaccronbach Pearson correlation coefficient $\mathrm{R}$ Test of honesty and consistency in the tool to test the relationship between strategic leadership and organizational justice practices in Egyptian telecom companies and the simple linear regression model to determine the significance of the main hypothesis between strategic leadership practices and organizational justice for data analysis and access to the results of the study. Study Results A set of recommendations was proposed and proposals for future studies related to the research issue we Presented,

Key words: per formamce- strategic leadership- innovtion- creativity

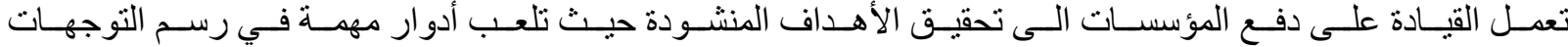

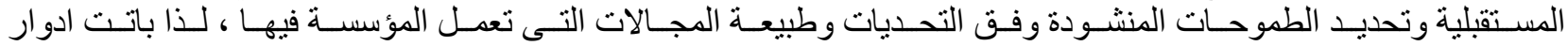

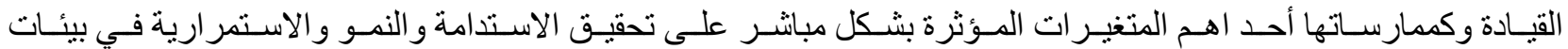
الاعمال المختلفة.

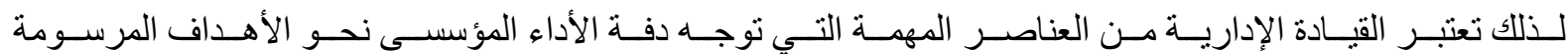

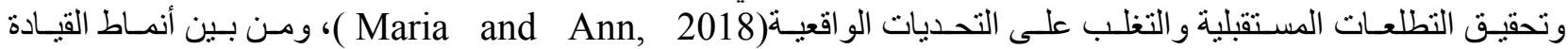

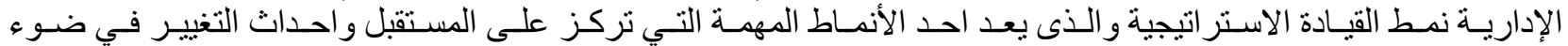

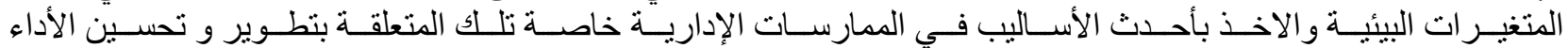
التنظيمى وجميع العناصر المؤثرة عليه( Arthur, et al., 2018 ).

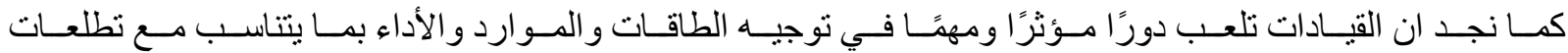

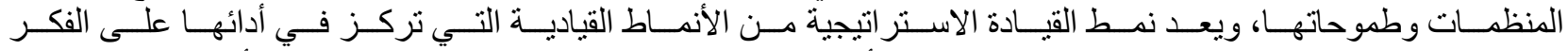

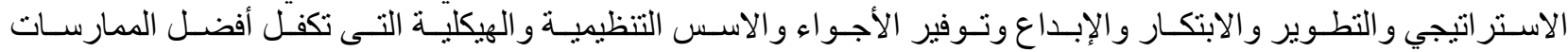
التنظيمية) (Jodi , and Sheila, 2017).

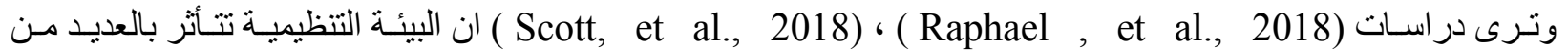

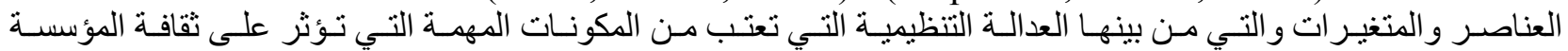

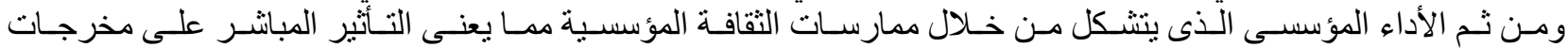
المؤسسة ودور ها تجاه الأطر اف أصحاب المصالح و العملاء.

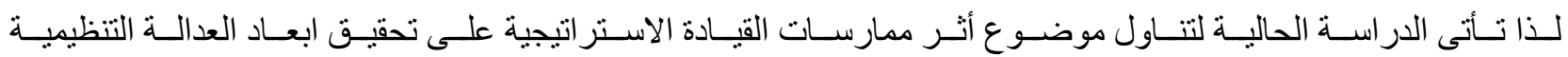
للمؤسسات در اسة تطبيقية على شركات الاتصالات المصرية. أهمية الاراسة تظهر أهمية الدراسة الحالية من الجوانب العلمية و النطبيقية التالية: 


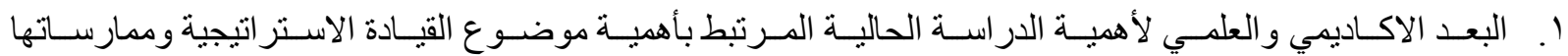

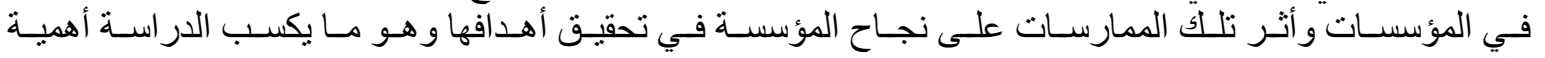
علمية.

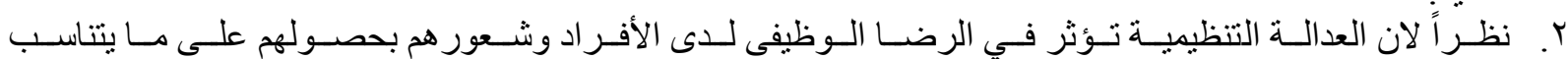

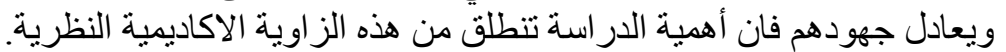

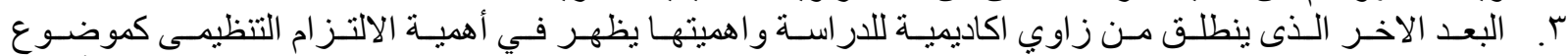

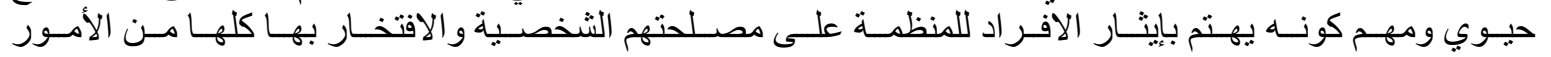
المهمة التى تصب في تحقيق اهداف المنظمة.

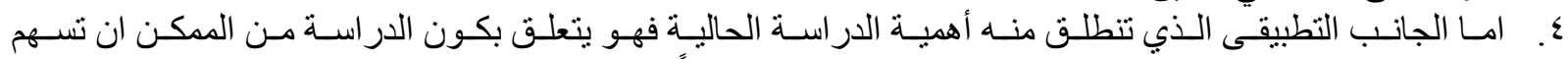

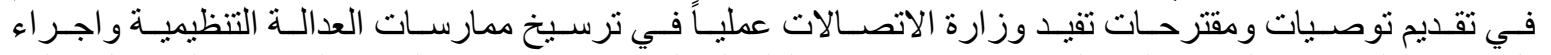

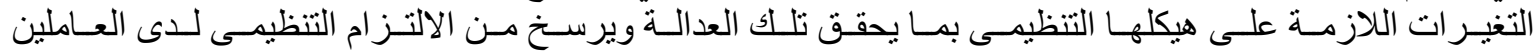

بالوزارة.

الار اسات السابقة

\section{القيادة الاستراتيجية}

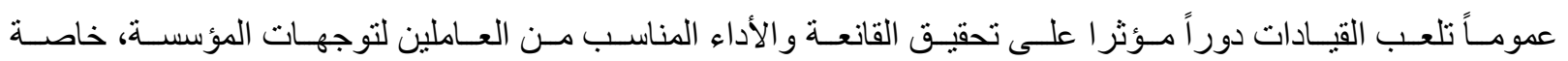

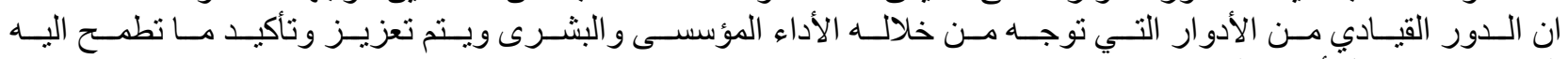
المؤسسة من خلال أدوار القيادات.

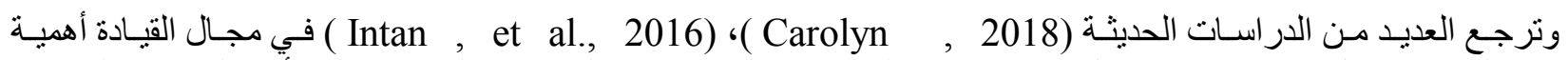

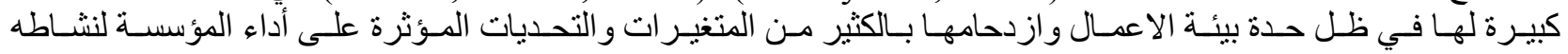
اليومي ومخرجاتها وطبيعة المنافسة التي تتعرض لهاع لها.

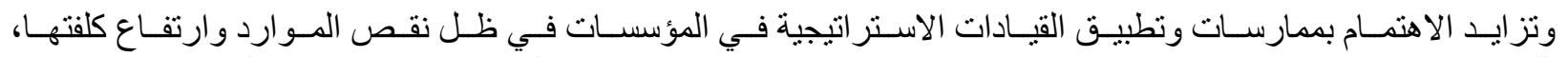

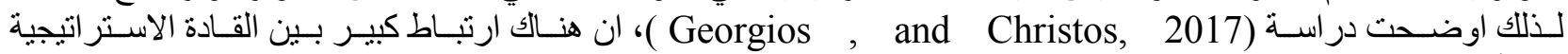

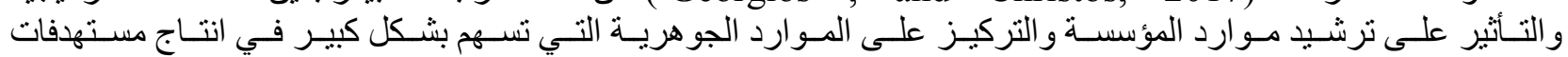

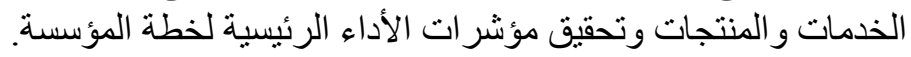

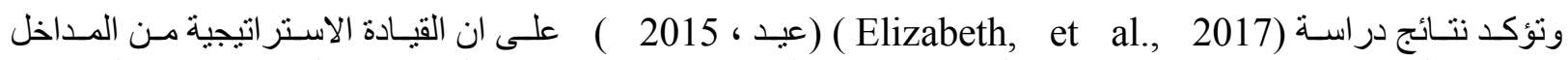

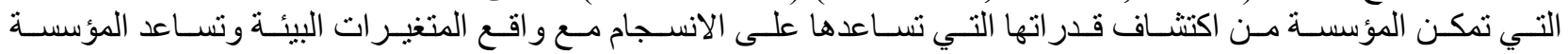

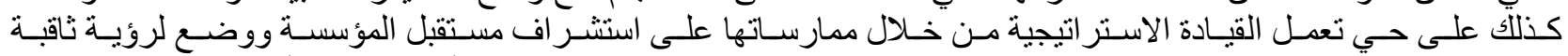


الاستدامة في بيئة العمل.

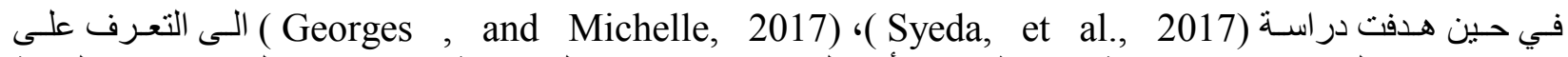

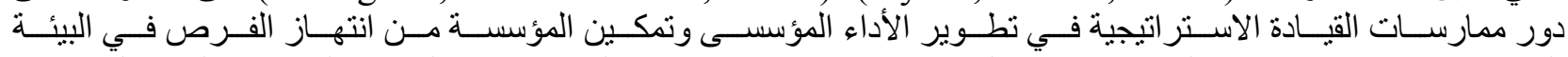

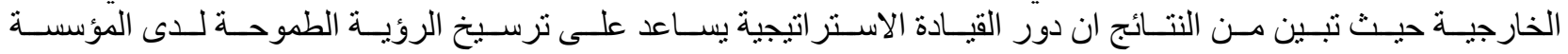

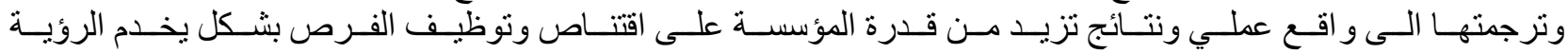
الاستر اتيجية التي وضنهتها المؤسسة.

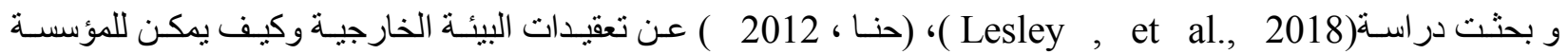

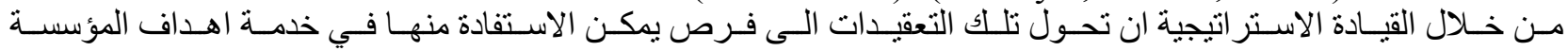

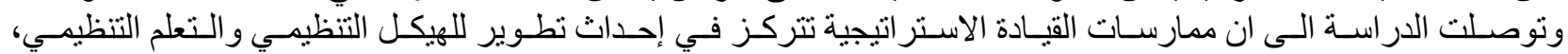

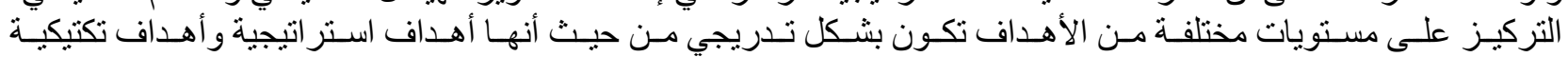

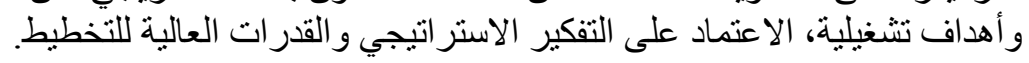

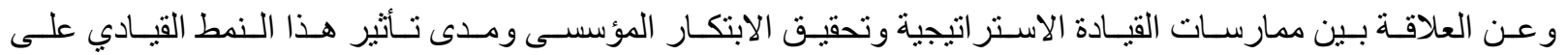

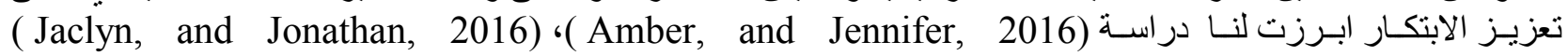

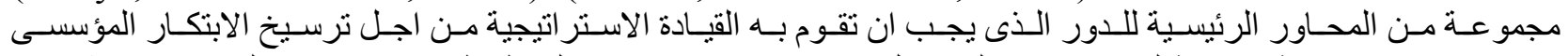

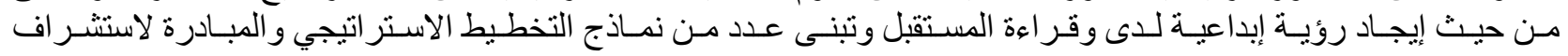




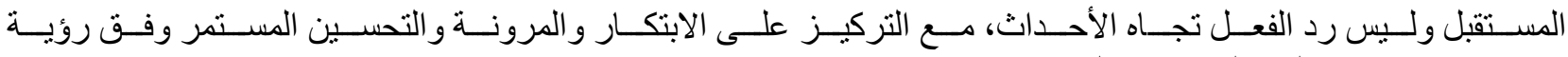
استر اتيجية وتحفيز و الهام المبتكرين بالمؤسسة.

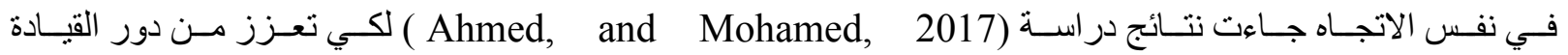

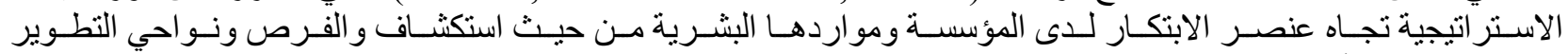

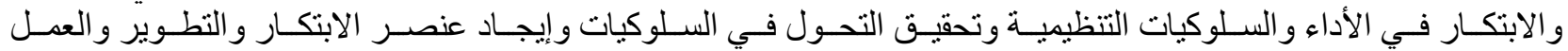

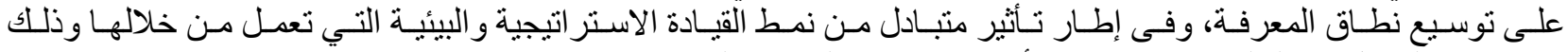
حتى يكون التحول في السلوكيات وتطوير الأداء منسجم مع النواحي البيئية(Elizabeth, et al., 2017 ).

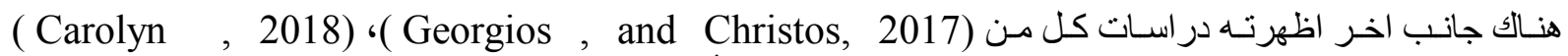

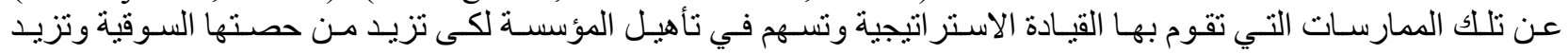

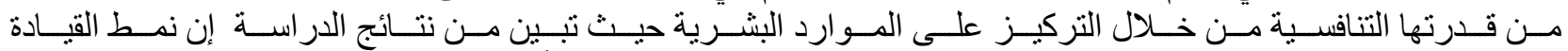

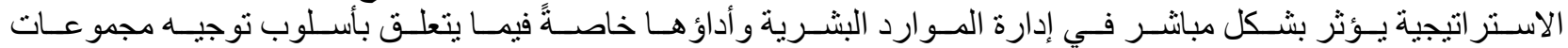

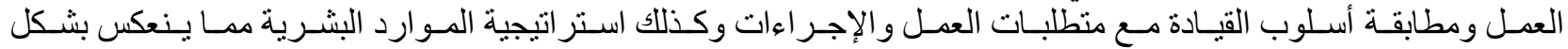


المو ارد البشرية.

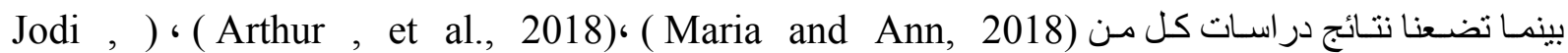
( and Sheila, 2017

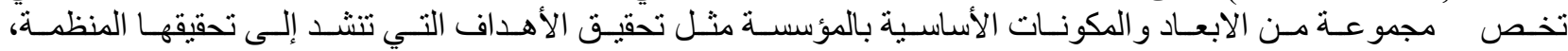

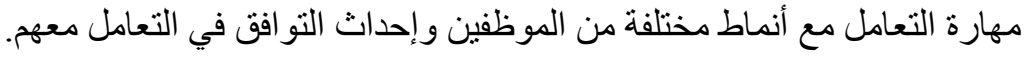

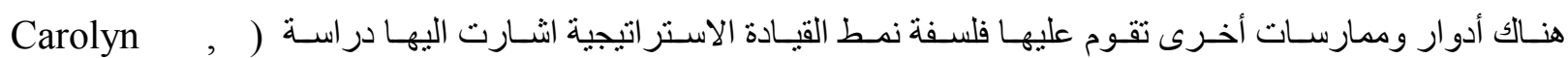

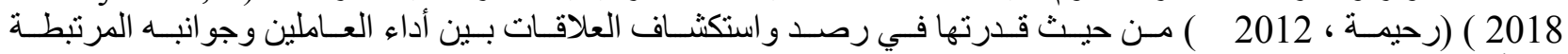

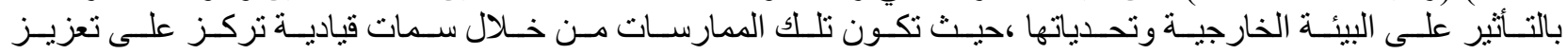
العلاقات فى بيئة العمل وخارجها وفق الطموحات المستقبلية للمؤسسة والافر اد.

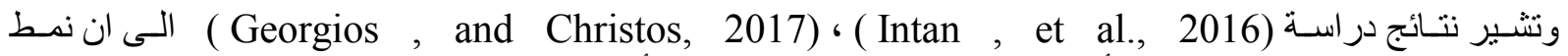

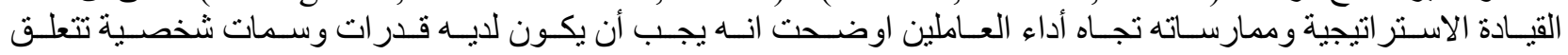

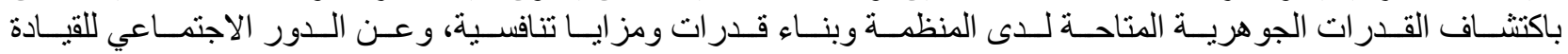

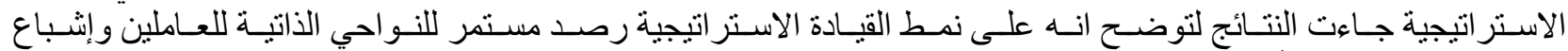
هذه الجو انب، هذا فضلاً أن يكون هنالك تأثيُ كاريز عالتي من القيادات ودور ملهم لأداء الموظفين.

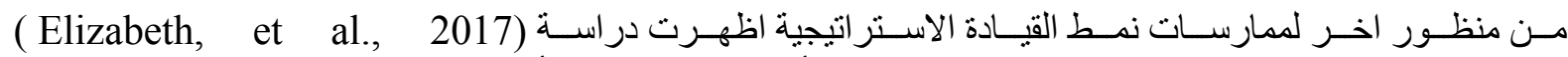

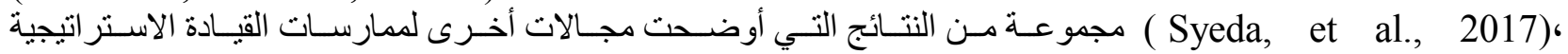

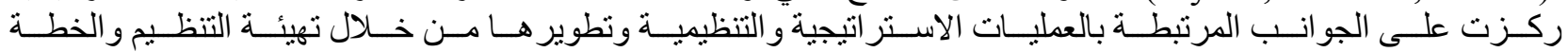

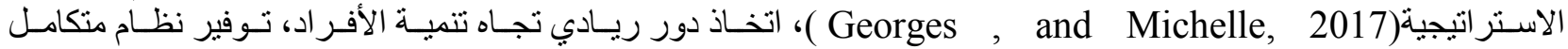

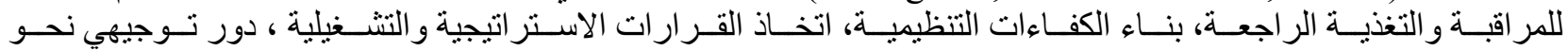
توظيف الموارد و الاستفادة منها في العمليات التشغيلية ، الارتقاء بمستويات النتائج المتحققة.

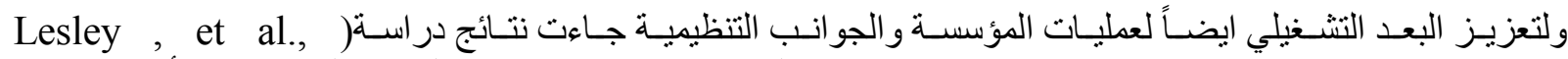

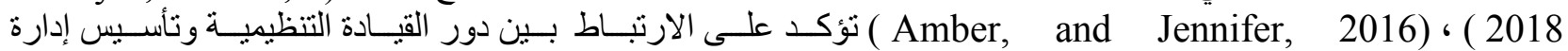

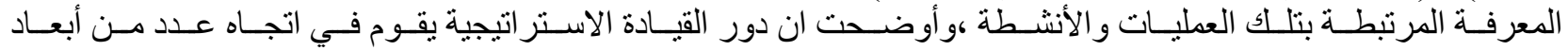

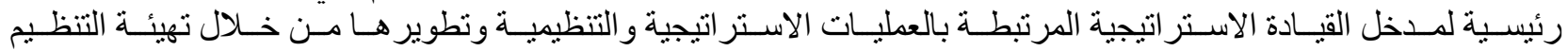

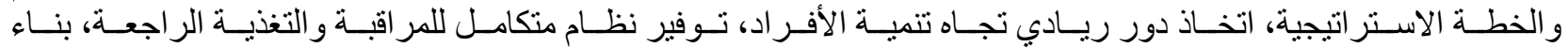

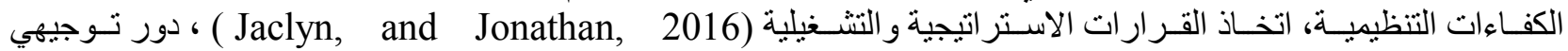

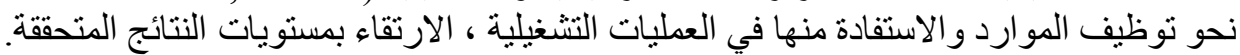

العدالة التظيمية

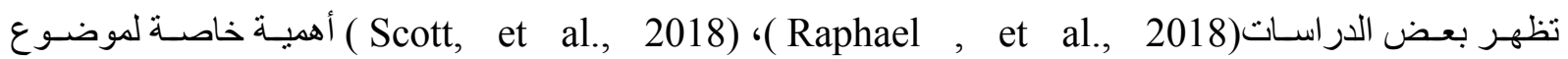

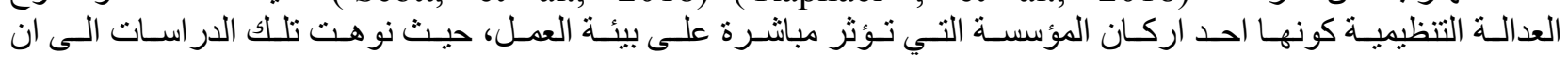




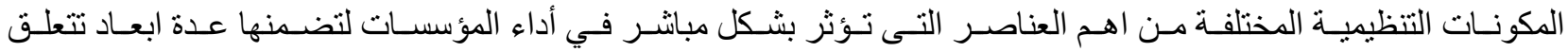

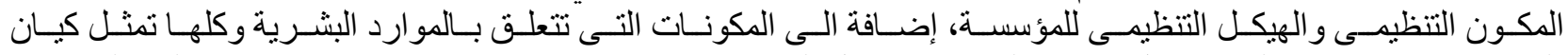

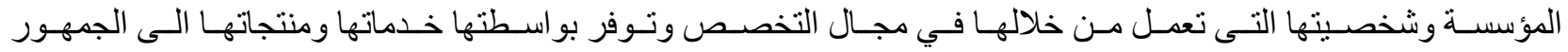

المستفبد منها.

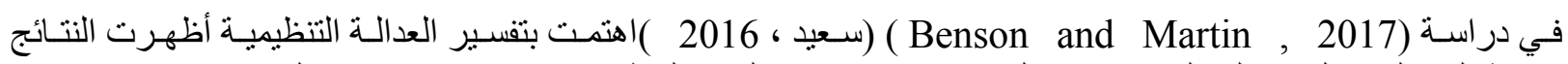

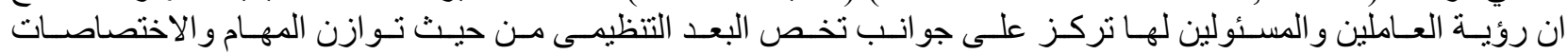

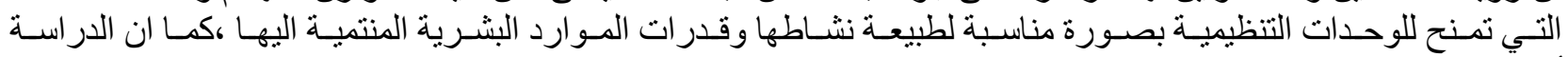

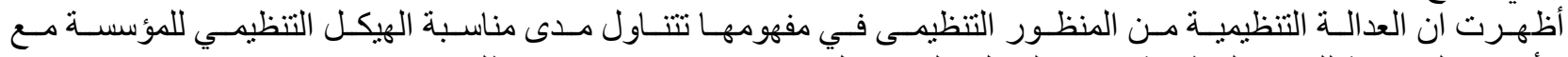

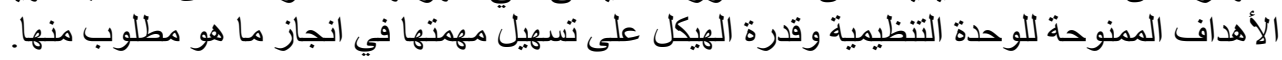

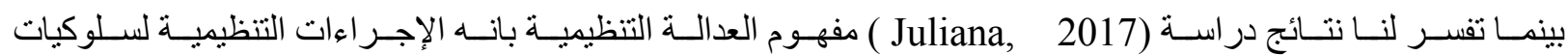

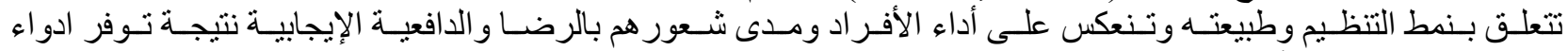

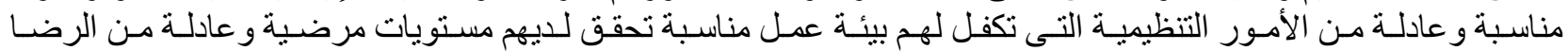

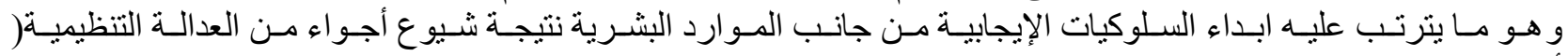

أبو تايه،2016).

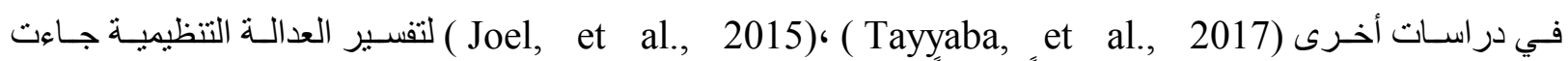

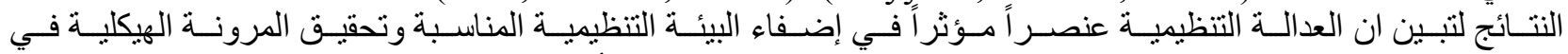

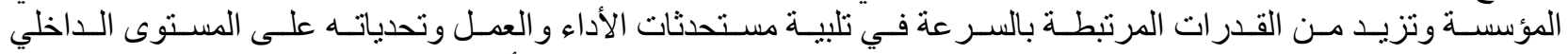

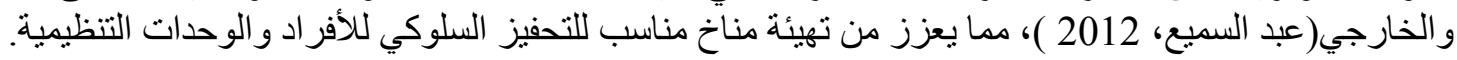

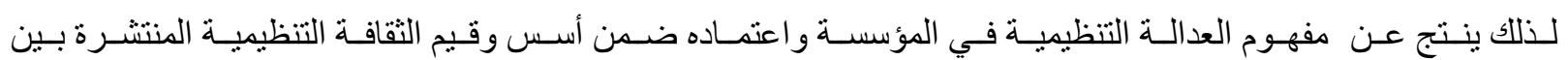

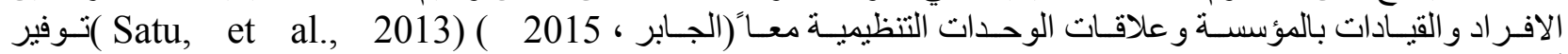

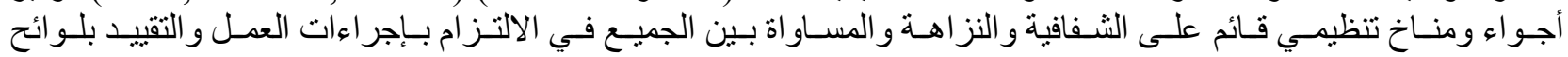
وقو اعد المؤسسة و الثقافة التنظيمية السائدة.

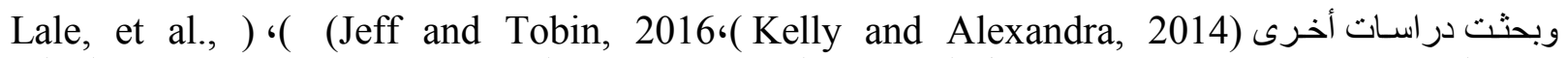

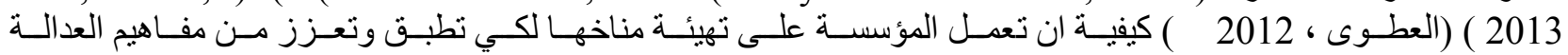

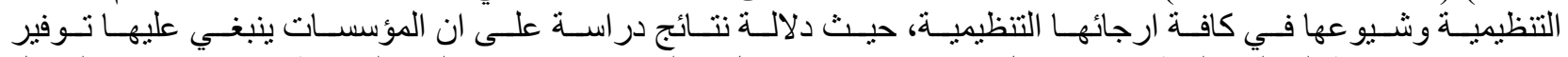

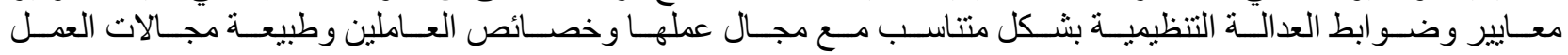

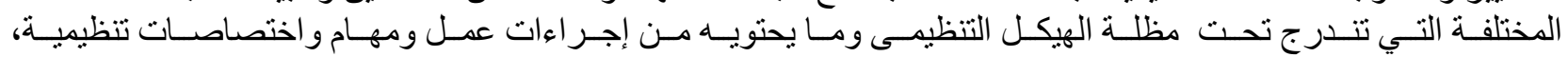
بحيث يكفل هذا النظام نشر ابعاد العدالة التنظيمية ومظاهر ها في ارجاء المؤسسة.

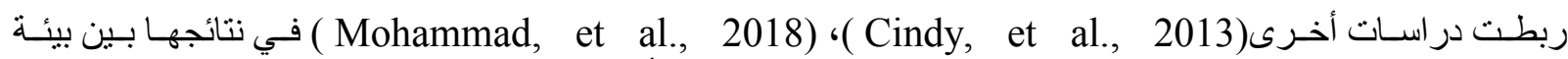

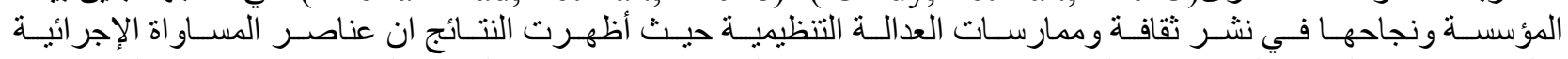

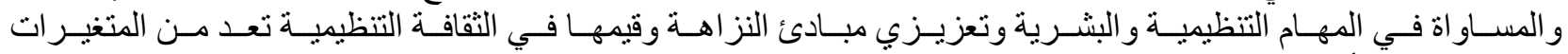

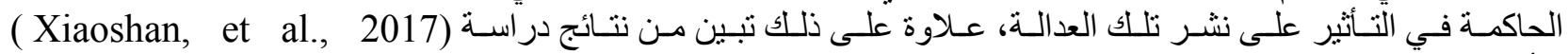

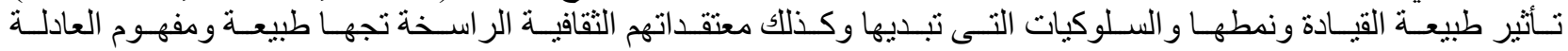
و المساو اة التنظيمية ومدلو لهائلادة لديهر.

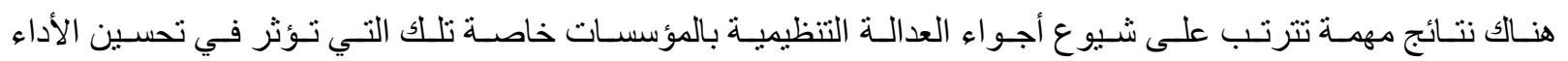

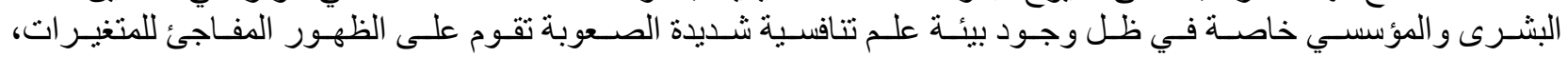

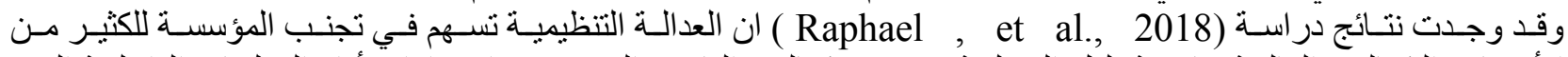

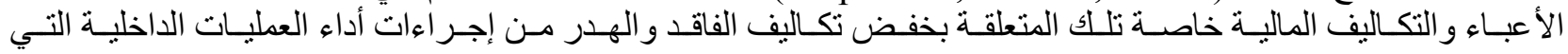

تمارسها المؤسسة ضمن نطاق عملها.



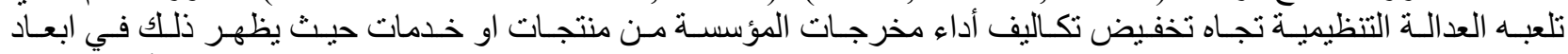

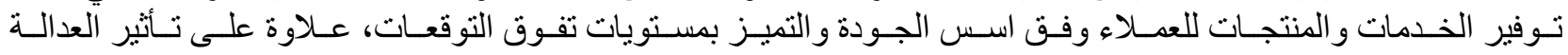

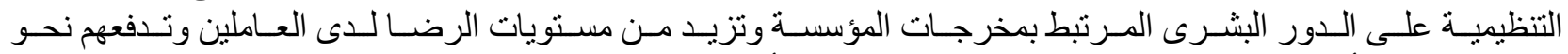
ابداء سلوكيات الأداء الو اعي المتو افق مع الإجر اءعات السليمة في أنشطة المؤسسة. 


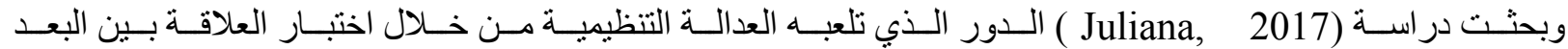

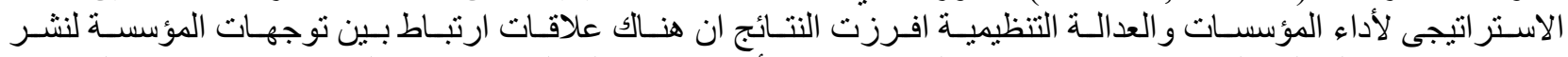

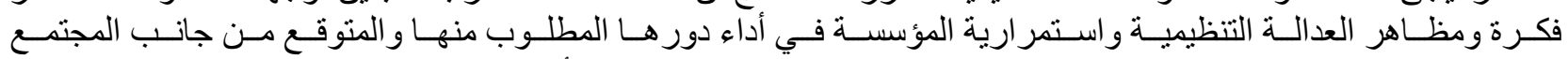

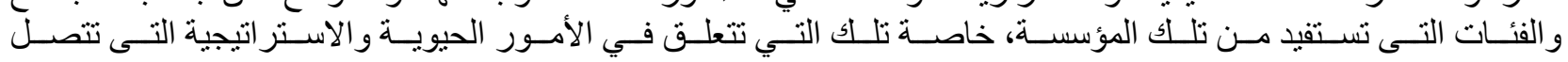

بالتنافسية وتحسين الصورة الذهنية في مجال عملها والاستحو اذ على ثقة المجتمع و العاملين فيها.

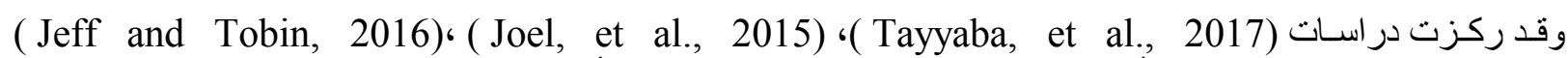

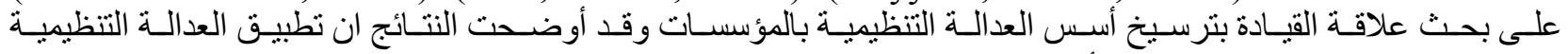

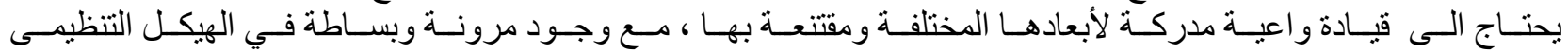

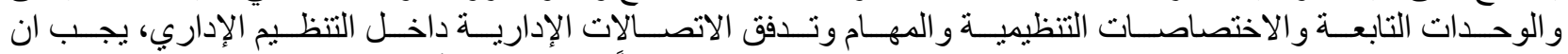

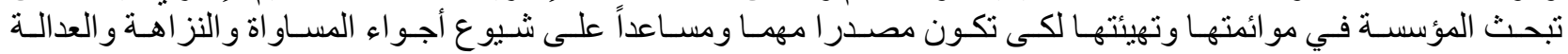

التنظيمية.

\section{التعليق على الاراسات السابقة}

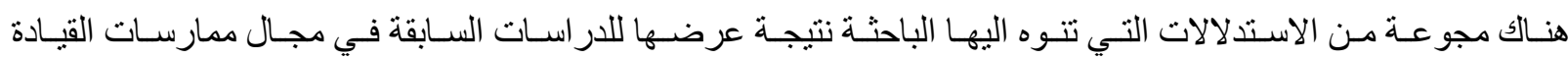
الاستر اتيجية و العدالة التنظيمية وهي كما يلّى الالى

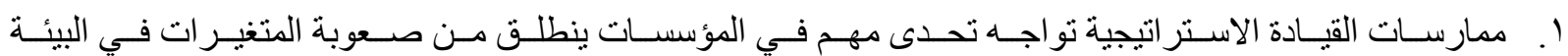

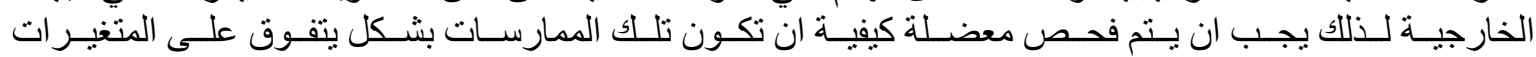
وطبيعتها.

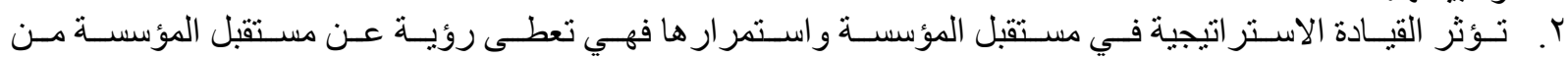

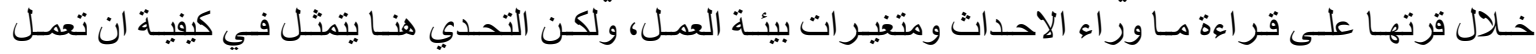

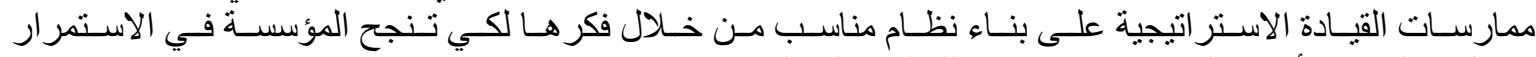

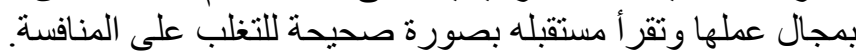

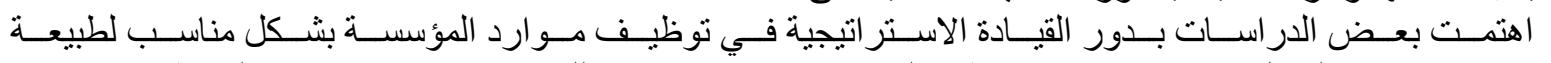

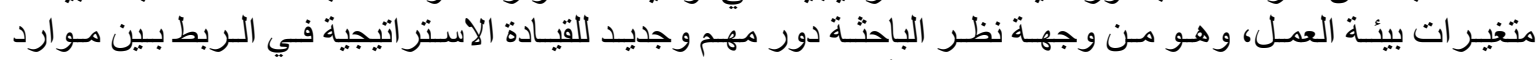

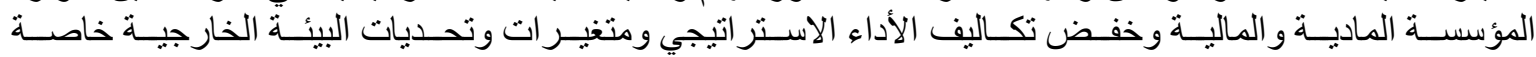

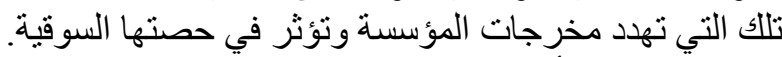

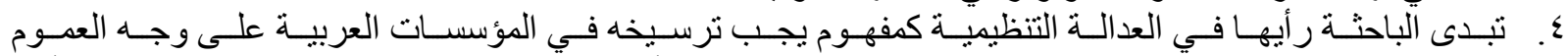

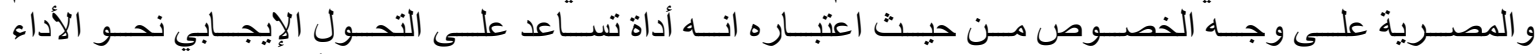

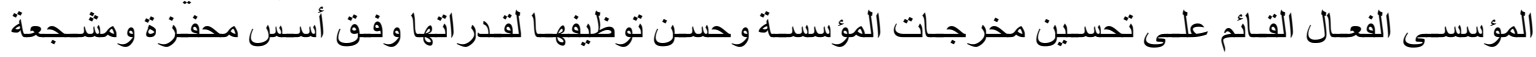

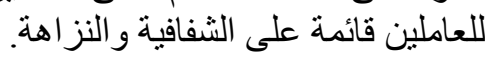

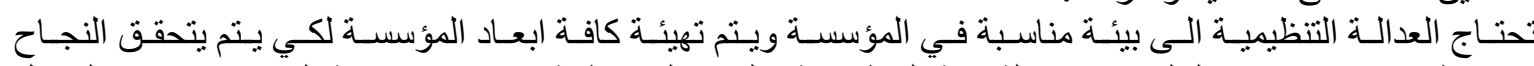

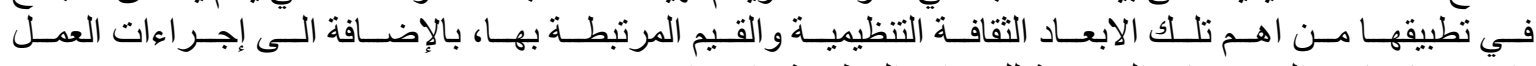

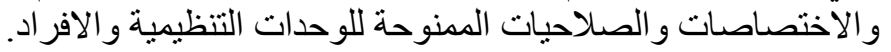

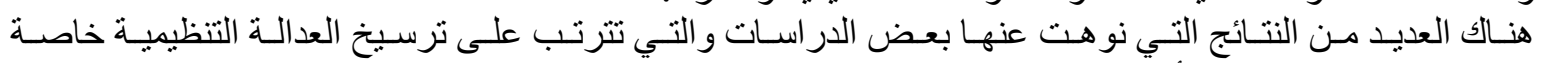

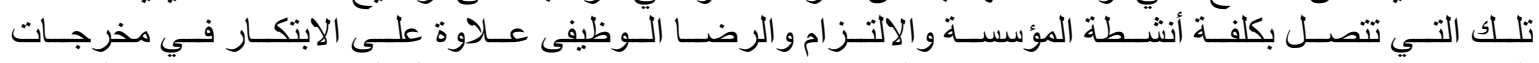

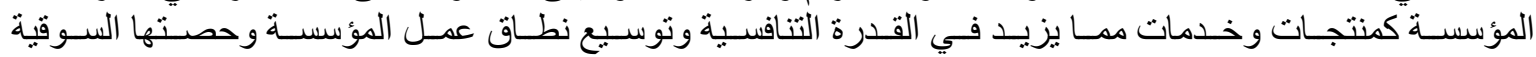
وثقة العملاء.

\section{المشكلة البحثية للاراسة}

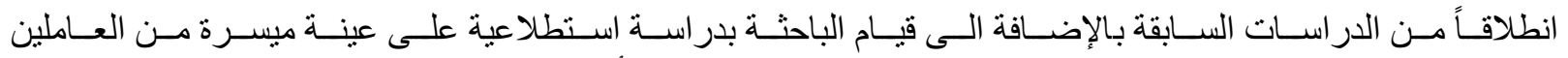

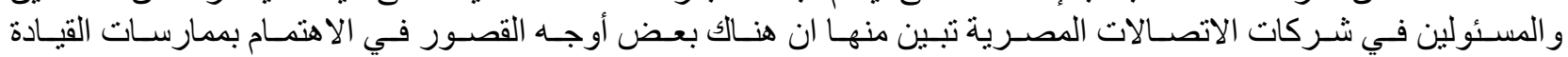

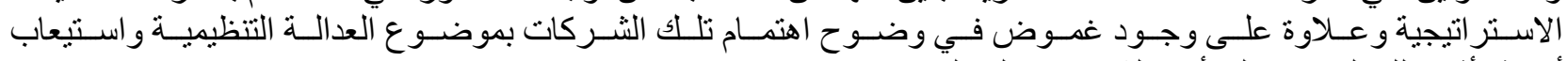
أهمية تأثير ذلك المفهوم على أداء الثى الثركات و العاملين.

$$
\text { لذلك تتبلور مشكلة الدراسة في محاولة الدراسة الحالية إيجاد إجابة للسؤال الرئيسي التالي }
$$

- ما اثر ممارسات القيادة الاستر اتيجية على تحقيق ابعاد العدالة التنظيمية فى شركات الاتصالات المصرية؟

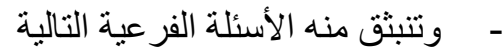




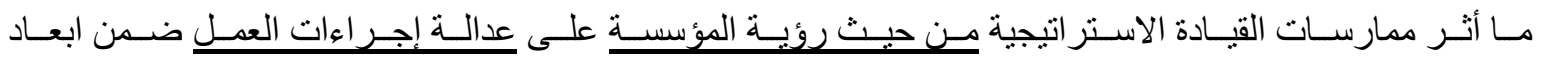

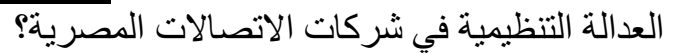

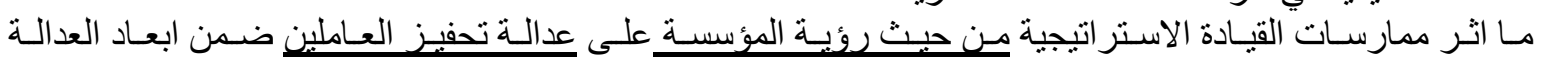
التنظيمية؛

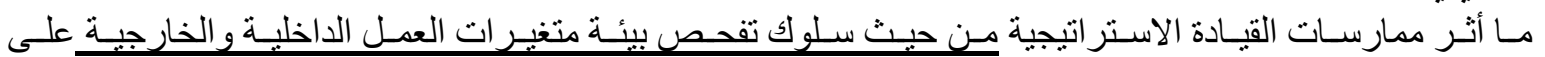

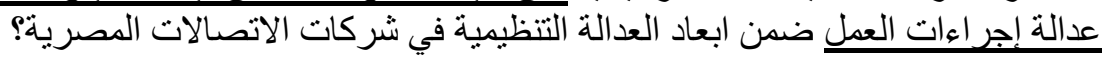

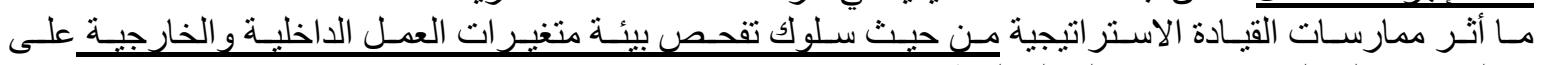

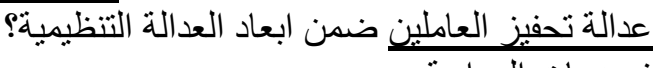
-

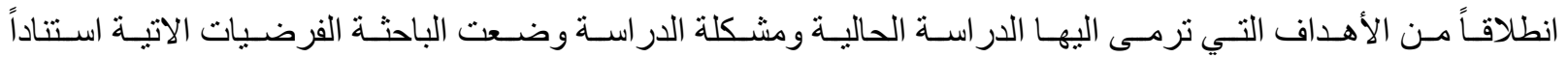


Raphael , )، (Georgios , and Christos, 2017 )، (Intan , et al., 2016 )، (Carolyn , 2018 )،) ‘(Juliana, 2017) (Benson and Martin , 2017)، (Scott, et al., 2018) ‘( et al., 2018 ( Joel, et al., 2015) ‘( Tayyaba, et al., 2017)

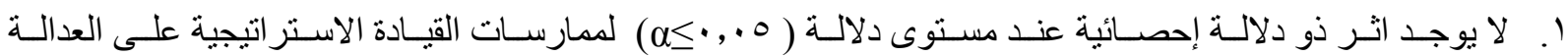

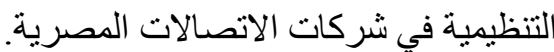

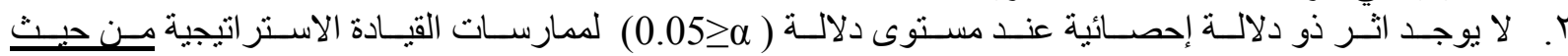

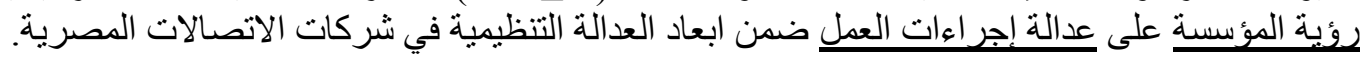

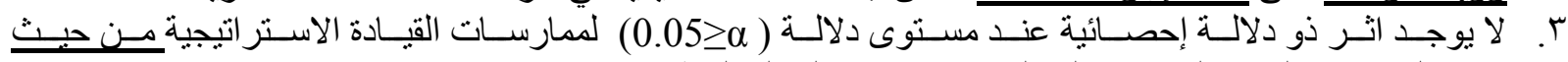

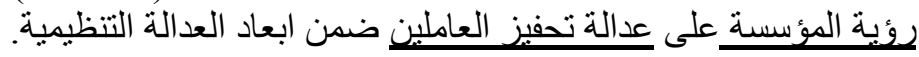

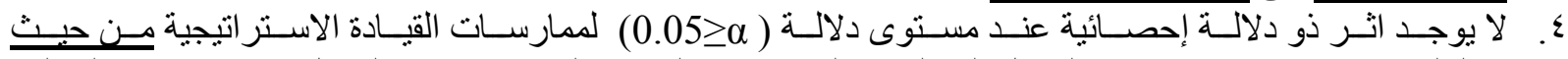

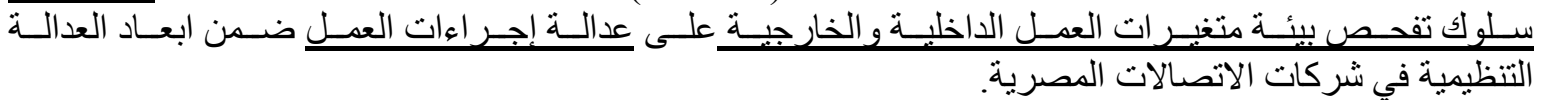

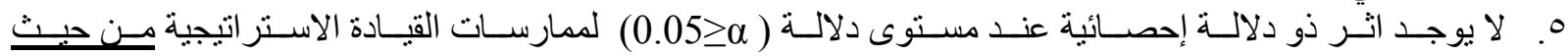

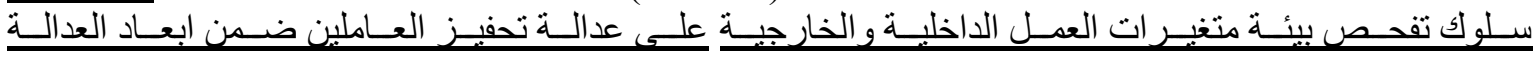
التنظيمية.

\section{تسعى الدراسة الحالية الى تحقيق مجموعة من الأهداف توضحها الباحثة كما يلى}

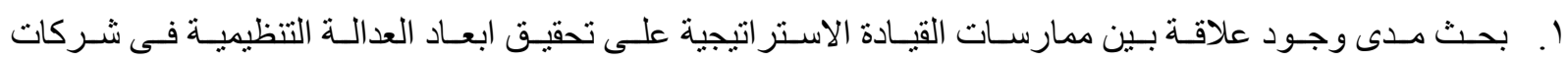
الاتصالات المصرية.

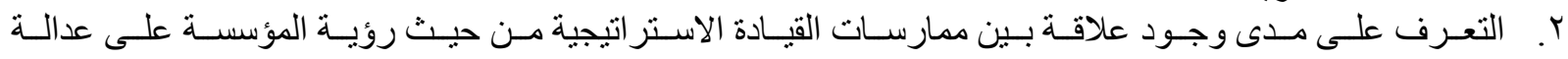

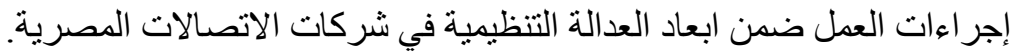

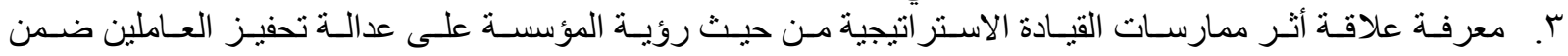
ابعاد العدالة التنظيمية.

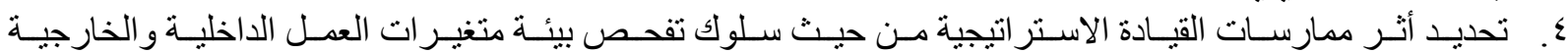

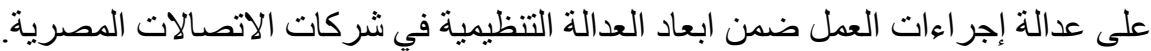

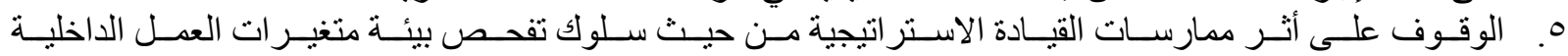
و الخارجية على عدالة تحفيز العاملين ضمن ابعاد العدالة التنظيمية.

\section{المصطلحات الإجرائية لمتغيرات الدراسة :- \\ القيادة الاستراتيجية}

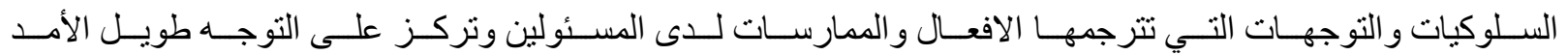

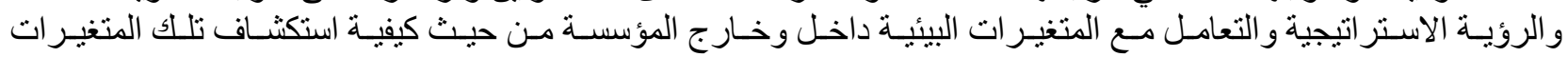

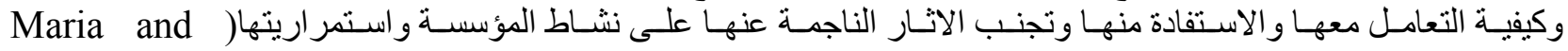


- ممارسات القيادة الاستراتيجية من حيث سلوك تفحص بيئة متغيرات العمل الاخلية والخارجية

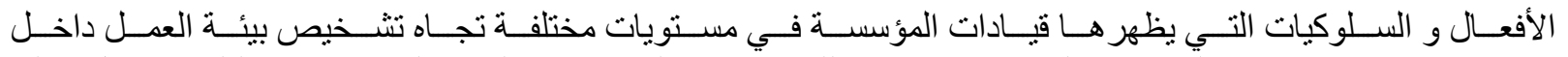

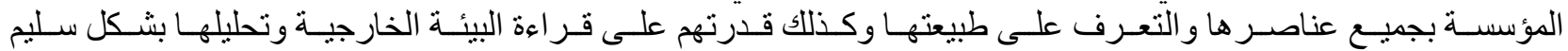

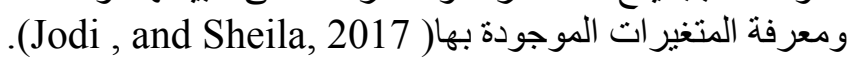

- ممارسات القيادة الاستراتيجية من حيث روئية المؤسسة

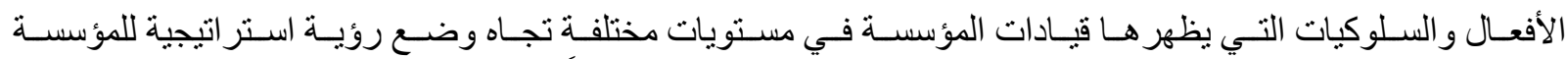

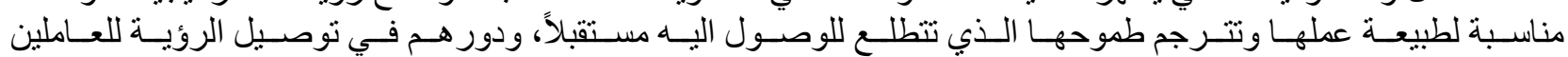

وتوجيهـم لتحقيقها (Arthur, et al., 2018).

\section{العدالة التظظيمية}

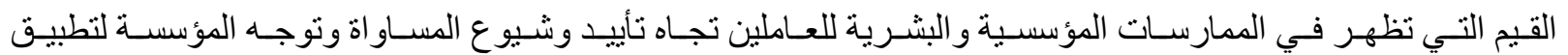

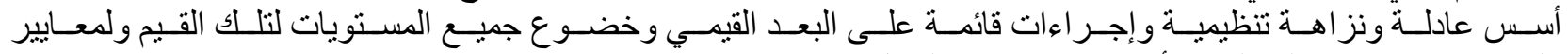
ولو ائح موحدة قائمة على البعد الأخلافي و الإنساني العادل(Raphael , et al., 2018 ).

عدالة الإجراءات

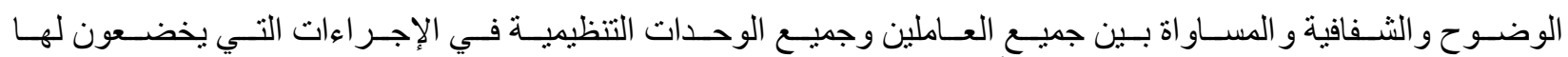
و المهام المنسوبة لهم وبما يشجع على تحسين الأداء وشيوع مناخ تنظيمي كف الو و عادل( Scott, et al., 2018) . - - عدالة تحفيز العاملين

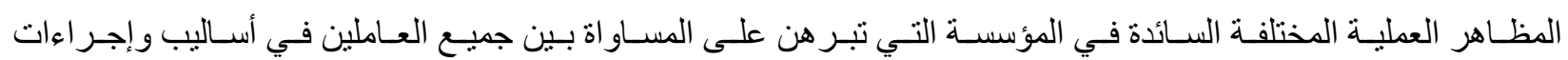

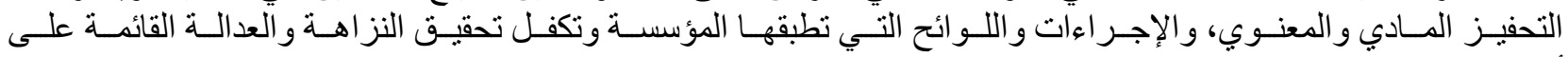
أسس منطقية في منح الحوافز المختلفة (Benson and Martin , 2017 )

$$
\begin{aligned}
& \text { منهجية الاراسة وتصميم الأداة: } \\
& \text { تشتمل منهجية الدراسة على الجو انب التالية } \\
& \text { أسلوب الدراسة والمنهج العلمي المستخدم :- }
\end{aligned}
$$

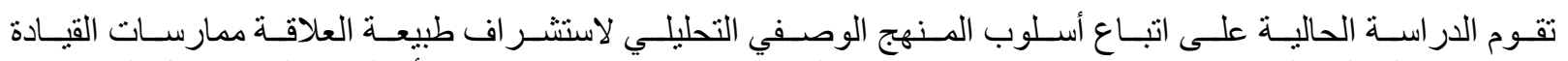

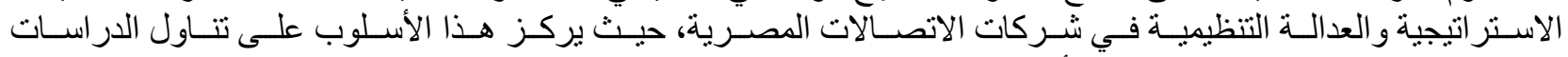

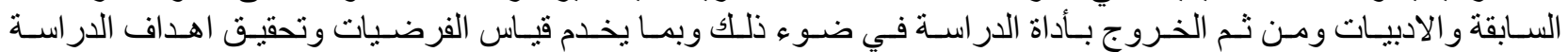
و الاجابة على المشكلة البحثية.

$$
\text { مجتمع الاراسة }
$$

يتمثل مجتمع الدر اسة فى شركات الاتصالات المصرية للمحمول.

$$
\text { عينة الدراسة :- }
$$



$$
\text { موزعين على الأربعة شركات . 10. } 10 \text { مفردة. }
$$

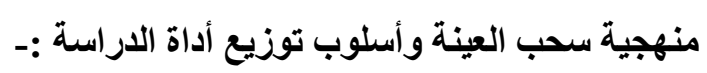

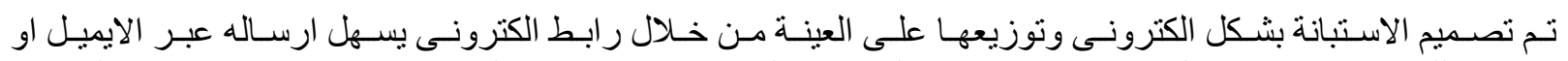

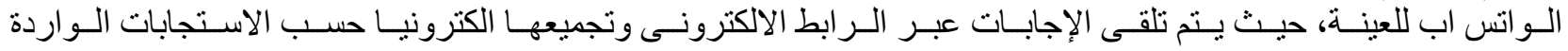
على الر ابط. 


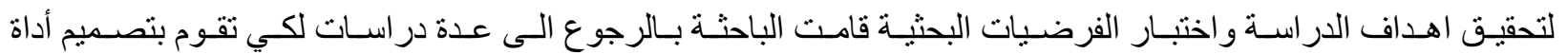

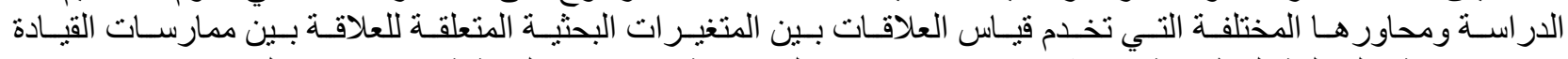

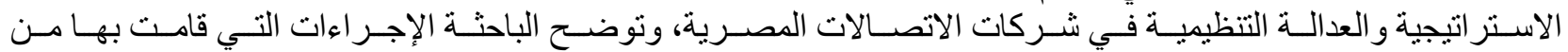
اجل تطوير أداة الدر اسة المستخدمة كما يلى: جدول (1 ) تصميم مقاييس أداة الاراسة

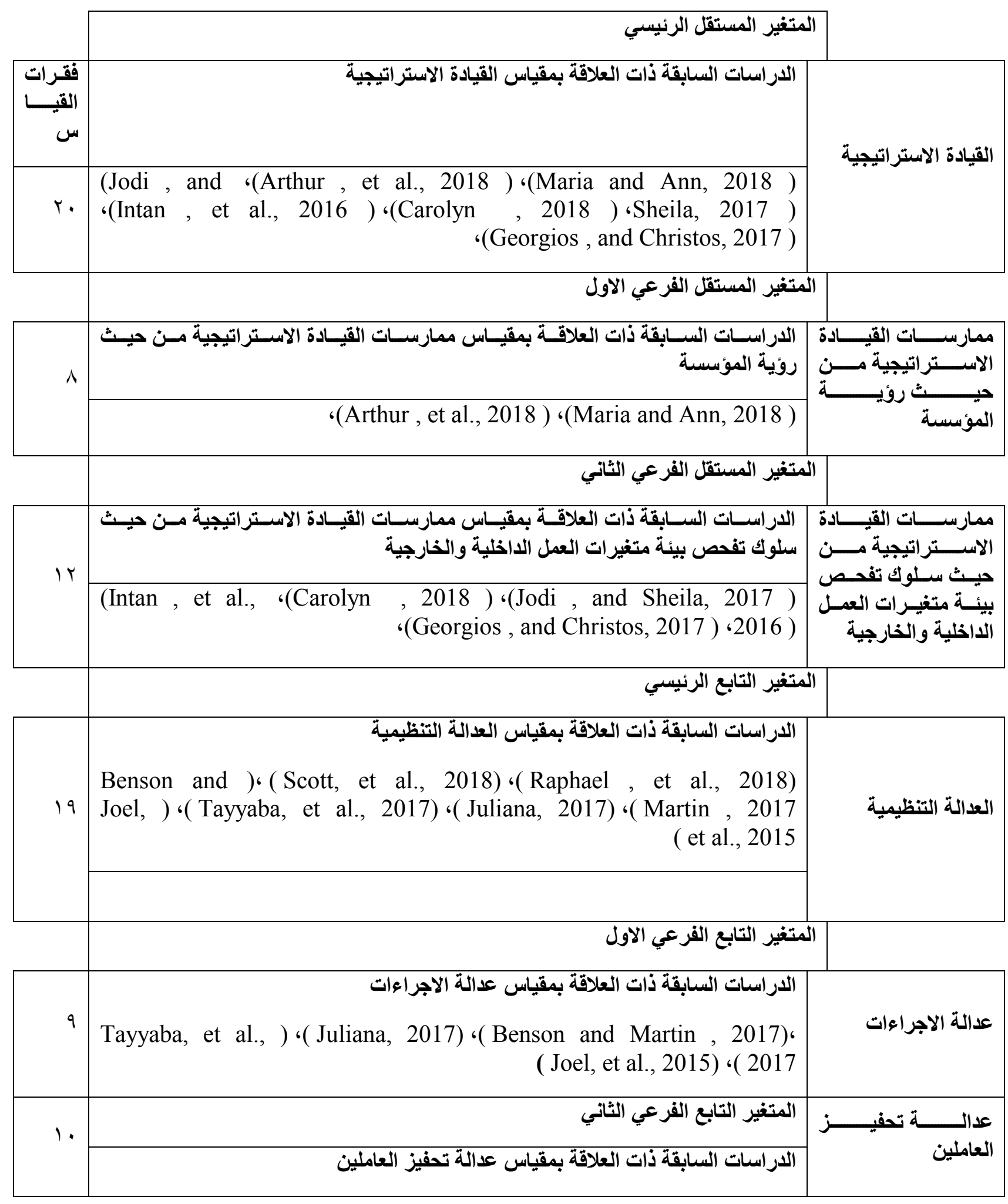


Scott, et ) ‘( Raphael , et al., 2018) ‘( Benson and Martin , 2017)

‘( Benson and Martin , 2017)، ( al., 2018

سؤال مفتوح عن معوقات ممارسات القيادة الاستر اتيجية والعدالة التنظيمية

سؤال مفتوح عن كيفية مواجه تلك المعوقات

قياس الثبات والصدق في أداة الدراسة :-

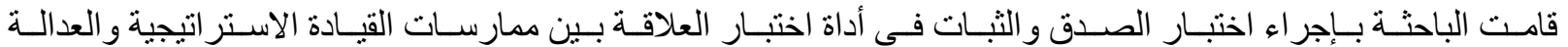

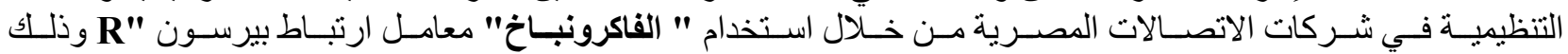
كما هو موضتح في الجدول التالي

جدول (ץ) متغيرات الدراسة وفقرات القياس والثبات والصدق لأداة الدراسة

\begin{tabular}{|c|c|c|c|}
\hline المحتوى Rـــــــ & الفاكرونباخ & مكونـــات & المتغيرات \\
\hline$(0.77)$ & 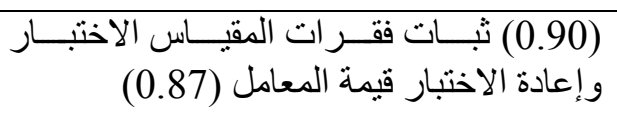 & 20 فقرة & ممارسات القيادة الاستراتيجية \\
\hline$(0.80)$ & 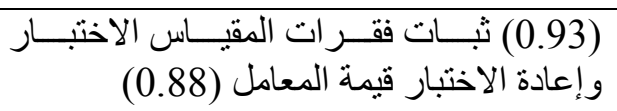 & 8 فقرات & روئة المؤسستة القيــادة الاســتراتيجية مـن حيــث \\
\hline$(0.78)$ & 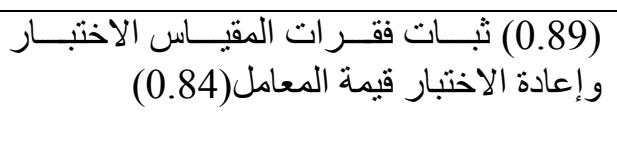 & 12 فقرة & 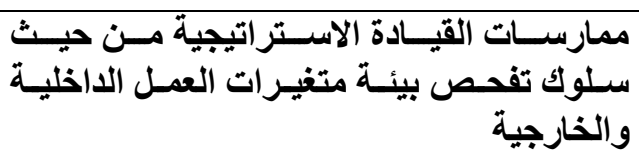 \\
\hline$(0.82)$ & 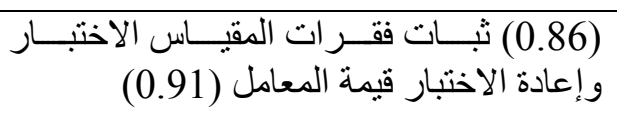 & 19فقرة & العدالة التنظيمية \\
\hline$(0.83)$ & 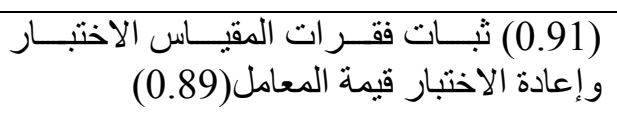 & 10 فقرة & عدالة تحفيز العاملين \\
\hline$(0.85)$ & 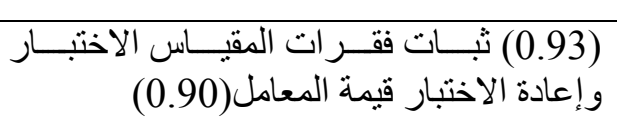 & 9 فقر ات & عدالة الاجراءات \\
\hline
\end{tabular}

نتائج الاراسة :-

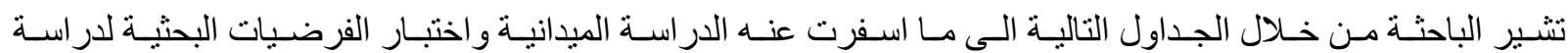

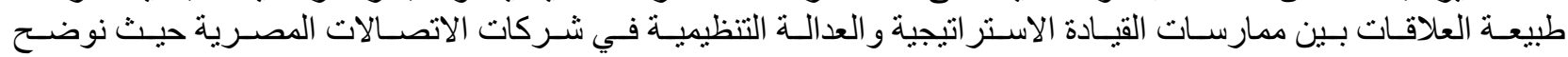
ذلك كما يلي:

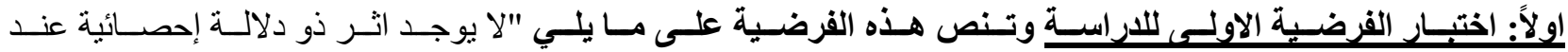

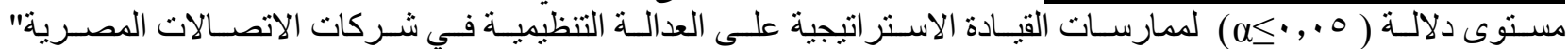




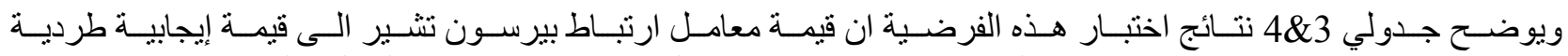

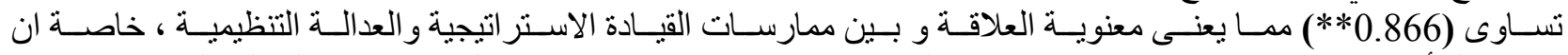

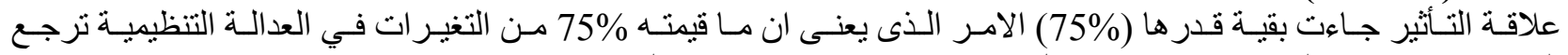

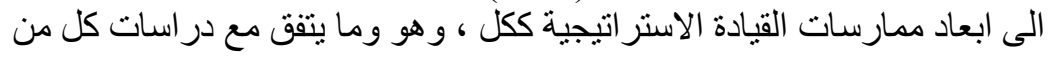

جـول رقـم (ّ) معامـل ارتبـاط بيرسـون لقيساس العلاقـة للفرضسية الاولسى بـين ممـارسـات القيـادة الاسـتراتيجية والعدالـة

\begin{tabular}{|c|c|c|c|}
\hline النتيجة الدلالة) & المعنوية & 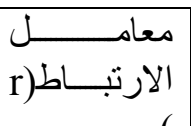 & العلاقة \\
\hline 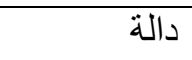 & $* * 0.0033$ & $* * 0.866$ & ممارسات القيادة الاستر اتيجية و العدالة التنظيمية \\
\hline
\end{tabular}

(0.05).

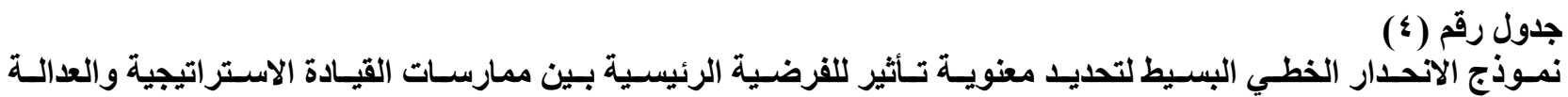

\begin{tabular}{|c|c|c|c|c|c|c|}
\hline \multirow{2}{*}{ 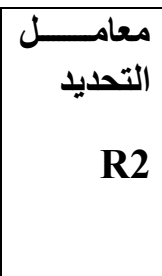 } & \multicolumn{2}{|r|}{ قيمة "ف" } & \multicolumn{2}{|r|}{$\begin{array}{l}\text { قيمة "ت" test } \\
\text { t. test }\end{array}$} & \multirow{2}{*}{$\begin{array}{c}\text { المقدرة } \\
\beta_{i} \\
\beta^{\prime}\end{array}$} & \multirow[t]{2}{*}{ المتغير المستقل } \\
\hline & المعنوية & 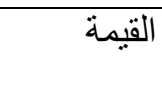 & المعنوية & القيمة & & \\
\hline $75 \%$ & $* * 0.0033$ & 431.823 & $* * 0.0033$ & 2.955 & 0.377 & ممارسات القيادة الاستر اتيجية \\
\hline & & & $* * 0.0033$ & 20.816 & 0.861 & \\
\hline
\end{tabular}

(0.05).

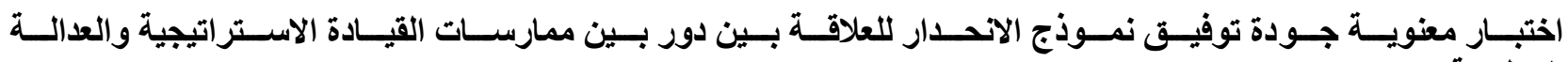

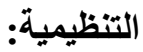

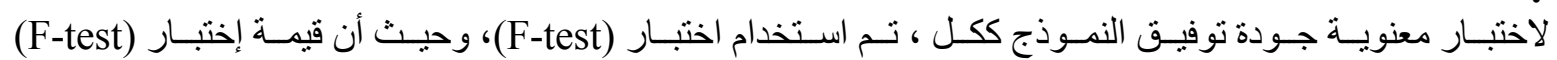

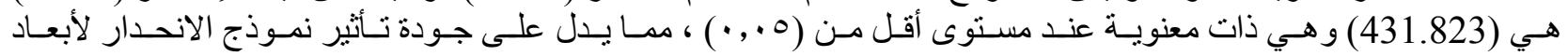

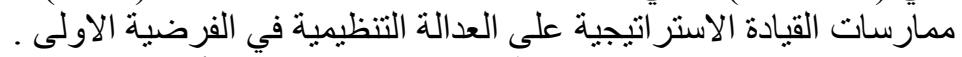

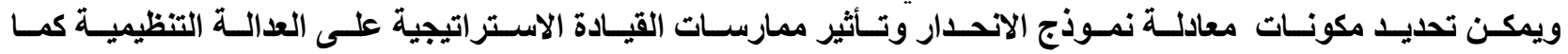
:ليلى : إنم: العدالة التظيمية = rVV

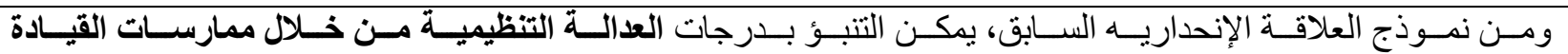

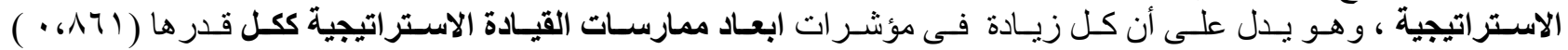

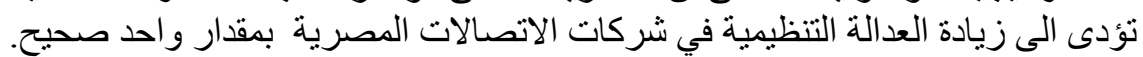

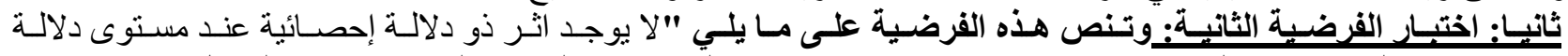

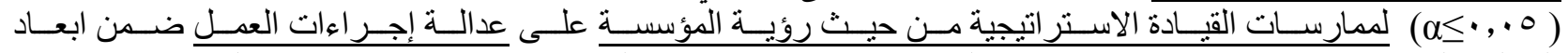

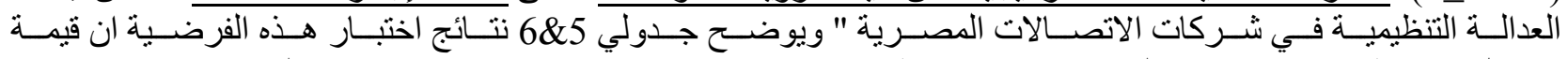

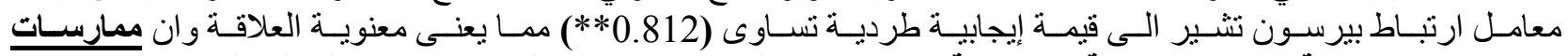

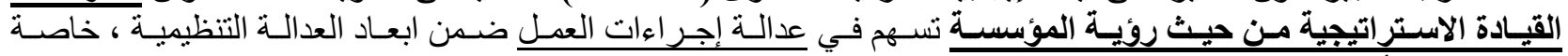

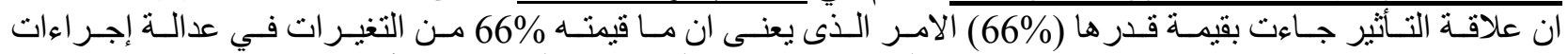

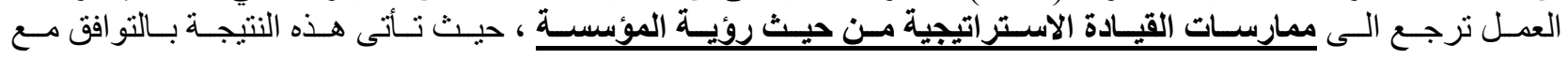




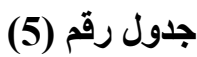

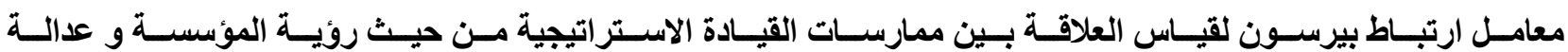
إجراءات العمل ضمن ابعاد العدالة التنظيمية في شركات بـين الاتصالات المصرية

\begin{tabular}{|c|c|c|c|}
\hline (النتيجة) & المعنوية مستوى & 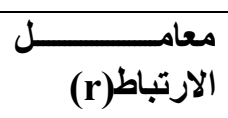 & الععلاقة \\
\hline دالة & $* * 0.009$ & $* * 0.812$ & 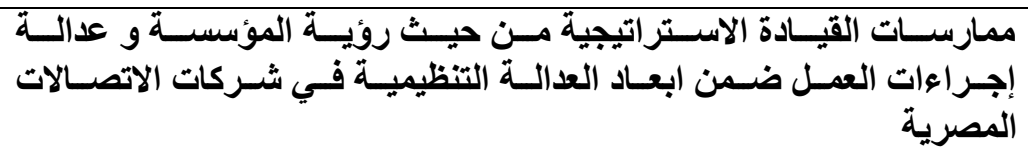 \\
\hline
\end{tabular}

جادرالة عند مستوى معنوية أقل من (0.05).

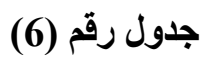

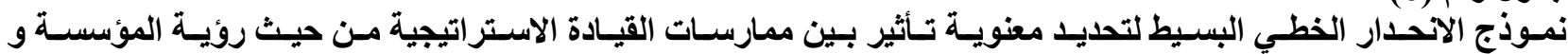

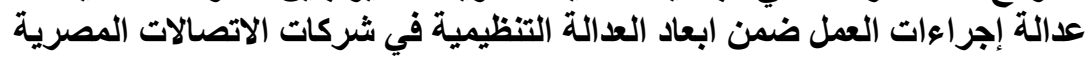

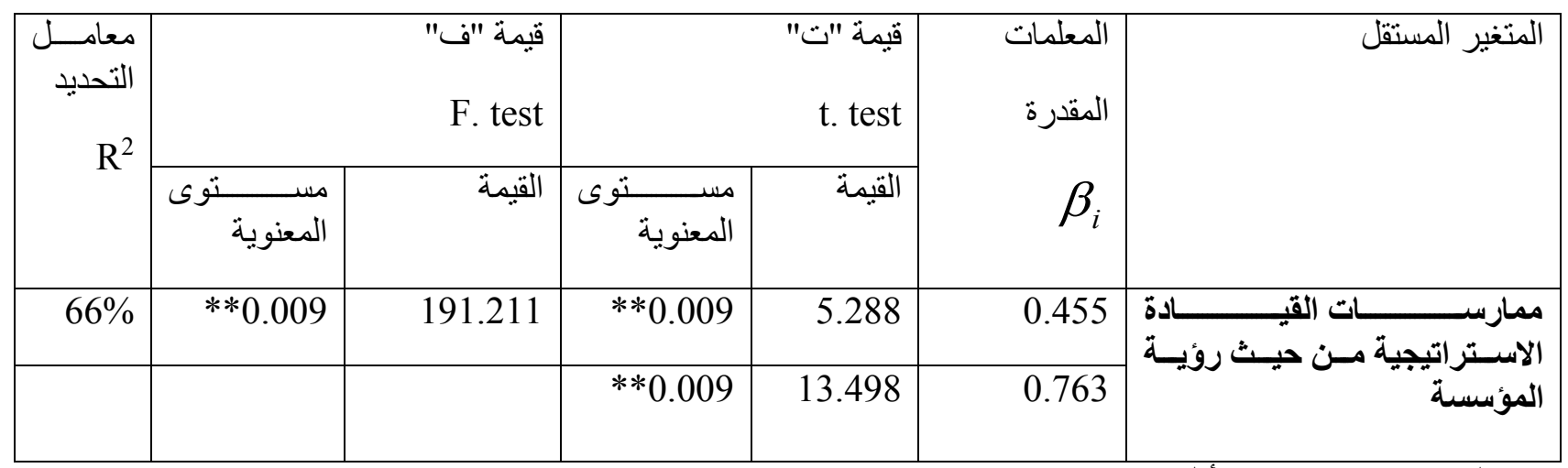

(0.05).دالة عند مستوى معنوية أقل من (0.05).

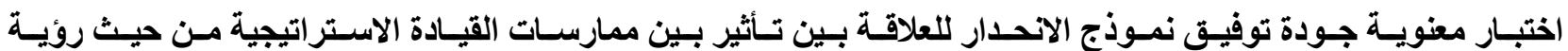

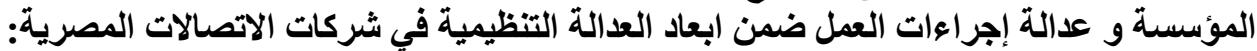

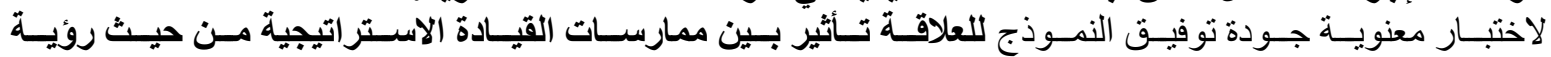

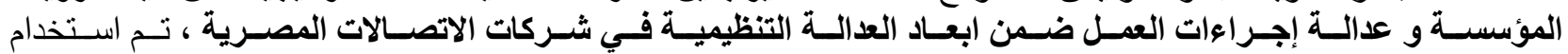

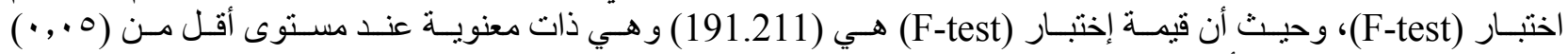

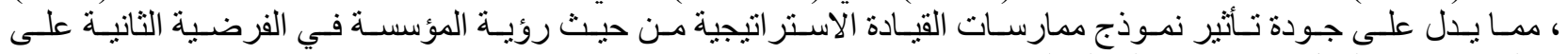

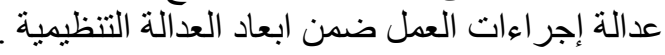

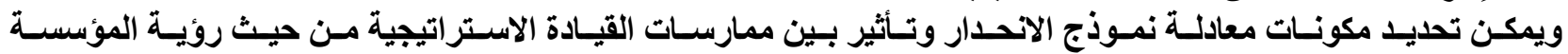

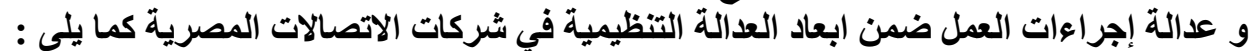

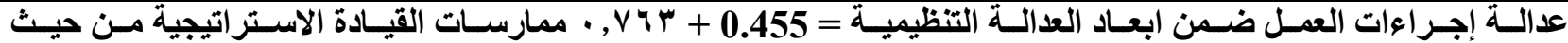
روئية المؤسسة الجرات

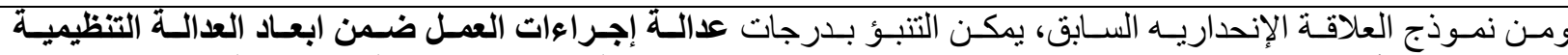

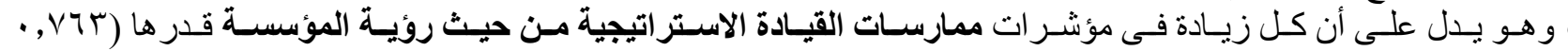

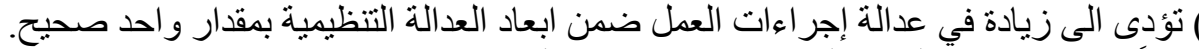

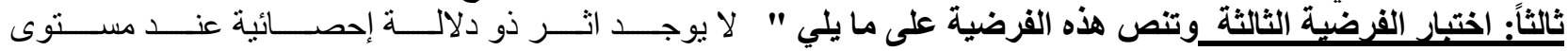

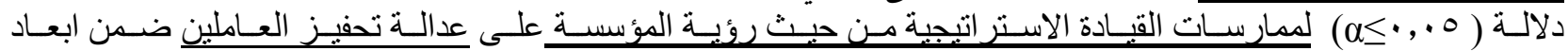

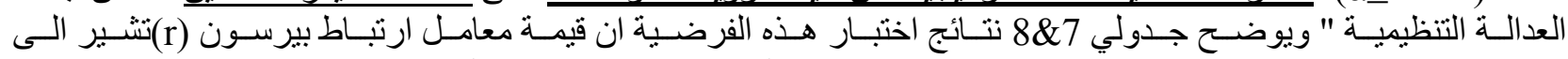

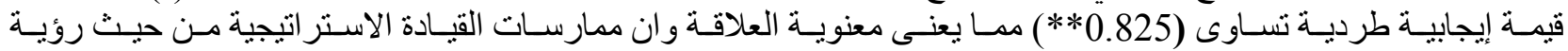

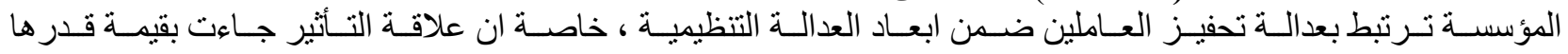

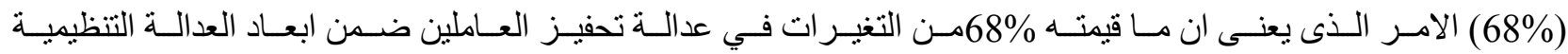
ترجع الى لممارسات القيادة الاستر اتيجية من حيث رؤية المؤسسة ، حيث تنفق تللك النتيجة مع در اسات . 
جدول رقم (7)


العاملين ضمن ابعاد العدالة التنظيمية في شركات الاتصالات بلتئ المصرية

\begin{tabular}{|c|c|c|c|}
\hline النتّنجة) & المعنوية مستوى & 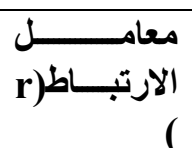 & العلاقة \\
\hline دالة & $* * 0.004$ & $* * 0.825$ & 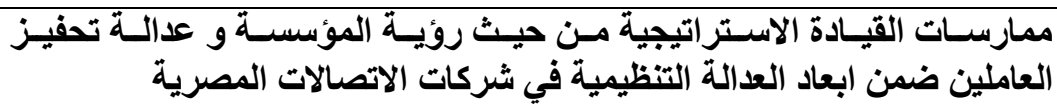 \\
\hline
\end{tabular}

(0.05)دالة عند مستوى معنوية أقل من(*).

جدول رقم (^)

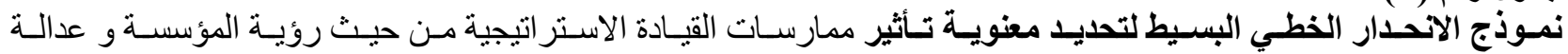

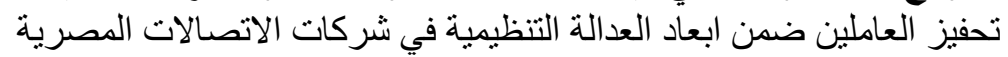

\begin{tabular}{|c|c|c|c|c|c|c|}
\hline \multirow{2}{*}{ 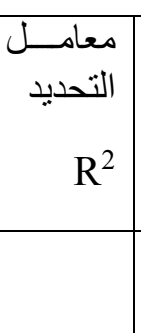 } & \multicolumn{2}{|r|}{ F. test } & \multicolumn{2}{|r|}{ t. test } & \multirow{2}{*}{$\begin{array}{c}\text { المعلمات } \\
\beta_{i} \\
\beta^{\prime}\end{array}$} & \multirow[t]{2}{*}{ المتغير المستقل } \\
\hline & المعنوية & القيمة & 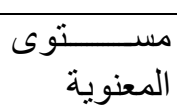 & القيمة & & \\
\hline $68 \%$ & $* * 0.004$ & 401.355 & $* * 0.004$ & 2.501 & 0.381 & 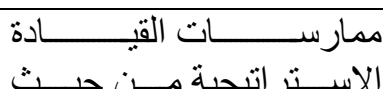 \\
\hline & & & $* * 0.004$ & 20.211 & 0.836 & رؤية المؤسسة \\
\hline
\end{tabular}

(0.05).

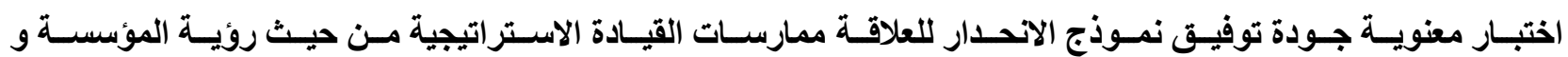

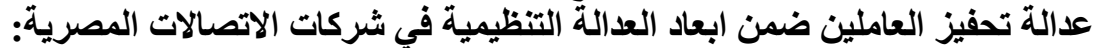

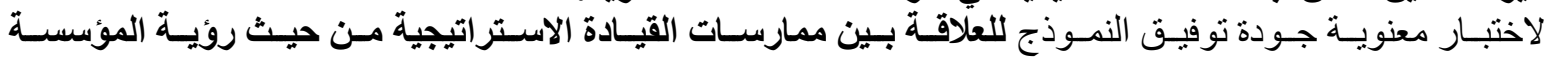

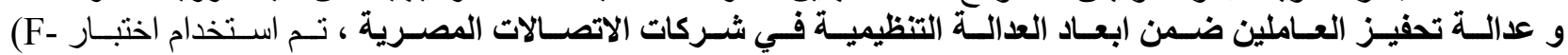

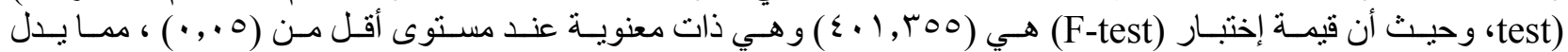

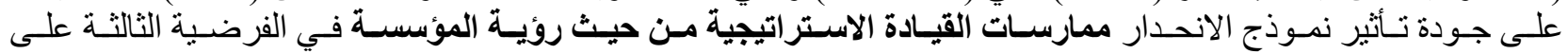

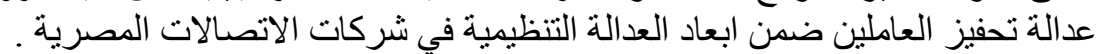

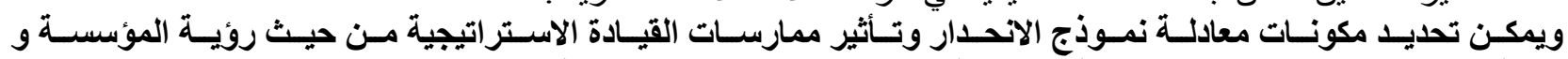

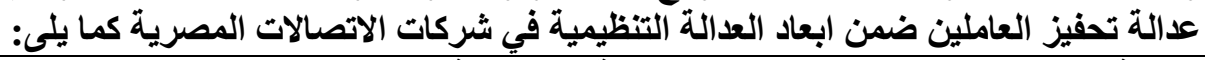

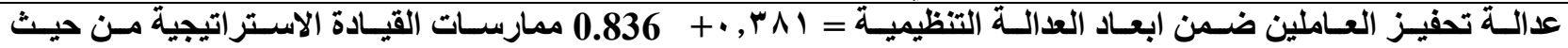
روية المؤسسة

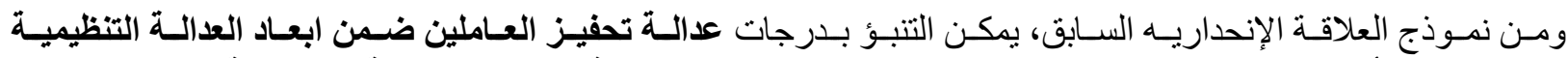

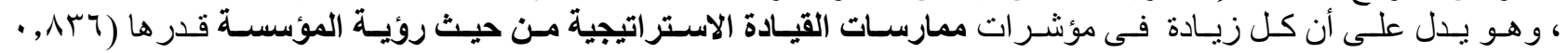

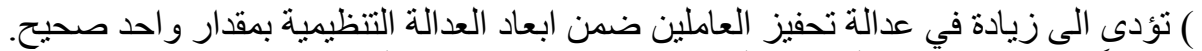

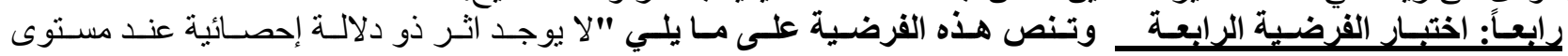

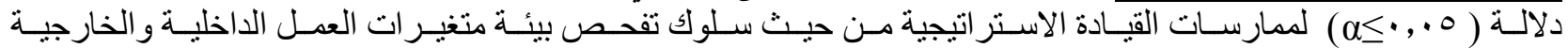

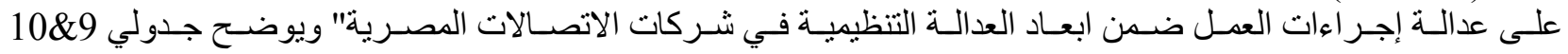




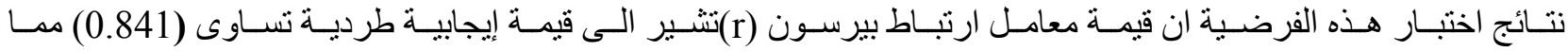

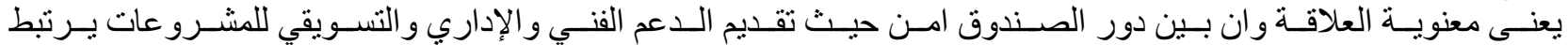

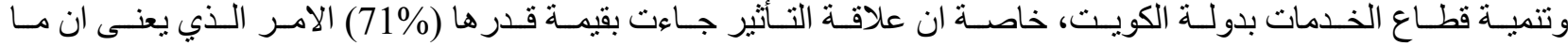

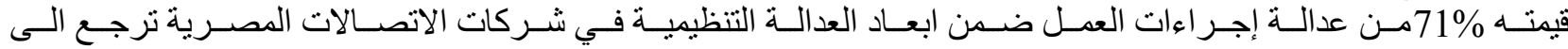
لممارسات القيادة الاستر اتيجية من حيث سلوك تفحص بيئة متغير ات العمل الدات الداخلية و الخارجية ، حيث يشير كل من.

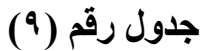

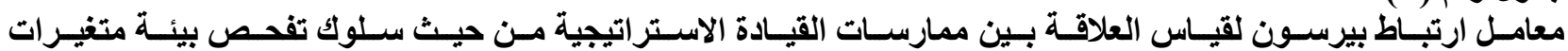

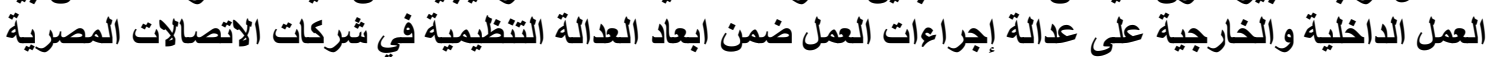

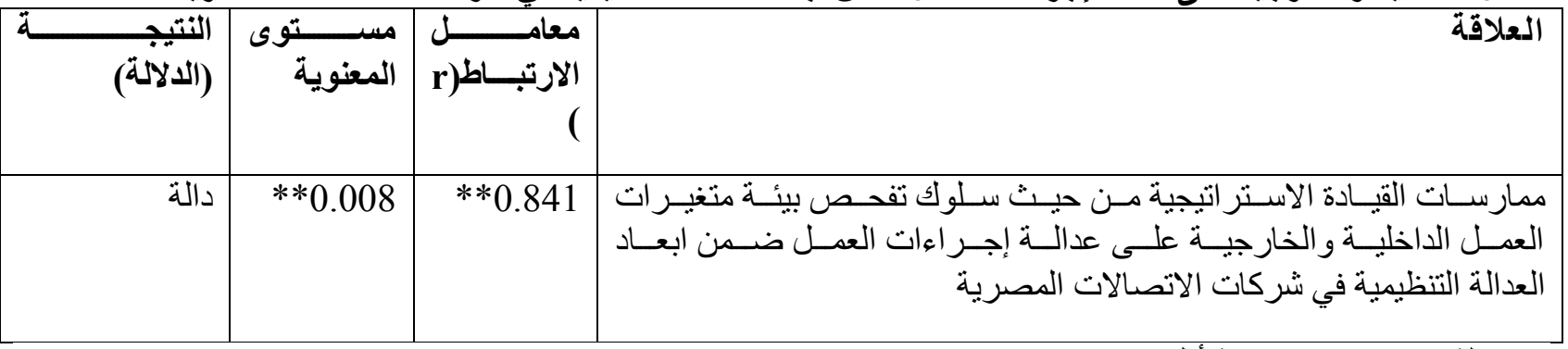

2*دالة عند مستوى معنوية أقل من (0.05).

جدول رقم (10) - (10)

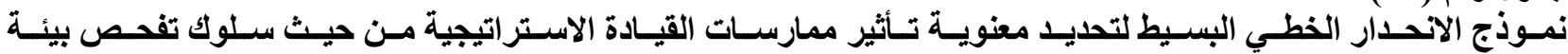

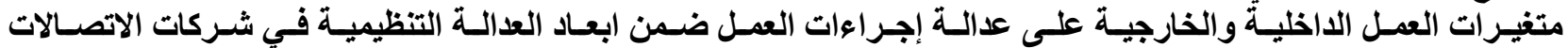
المصرية

\begin{tabular}{|c|c|c|c|c|c|c|}
\hline \multirow{2}{*}{ 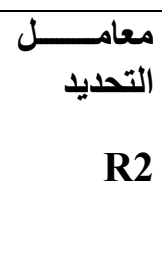 } & \multicolumn{2}{|r|}{ 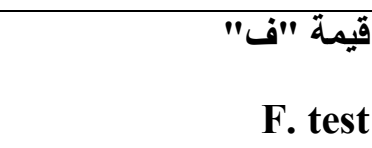 } & \multicolumn{2}{|r|}{$\begin{array}{l}\text { قيمة "ت" test } \\
\text { t. test }\end{array}$} & \multirow{2}{*}{$\begin{array}{c}\text { المقلمات } \\
\beta_{i} \\
\beta^{\prime}\end{array}$} & \multirow[t]{2}{*}{ المتغير المستقل } \\
\hline & المعنوية & القيمة & 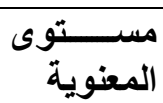 & القيمة & & \\
\hline \multirow[t]{2}{*}{$71 \%$} & $* * 0.008$ & 402.301 & $\begin{array}{r}* 0.008 \\
*\end{array}$ & 2.924 & 0.363 &  \\
\hline & & & $\begin{array}{r}* 0.008 \\
*\end{array}$ & 20.113 & 0.821 & \\
\hline
\end{tabular}

(0.05).

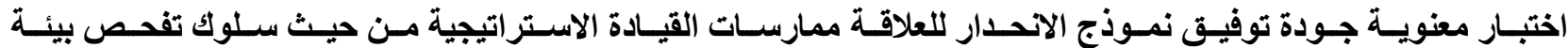

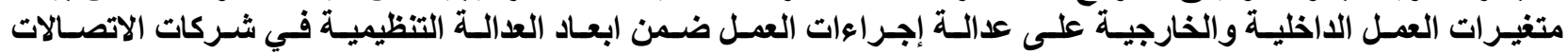

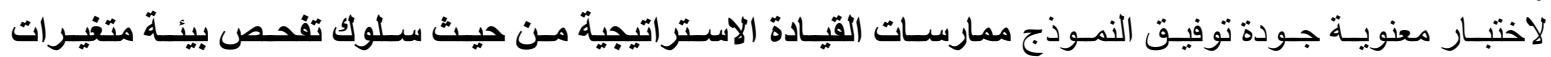

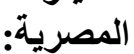

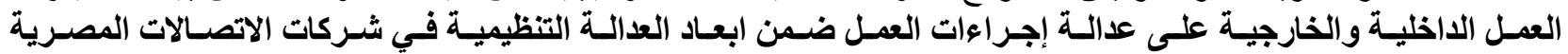

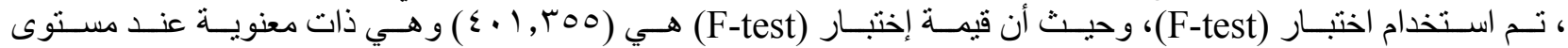

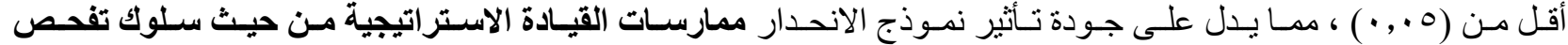

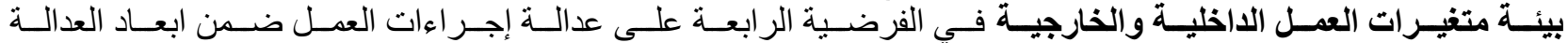

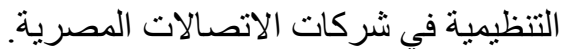

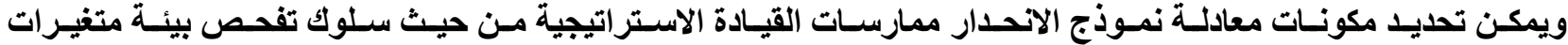

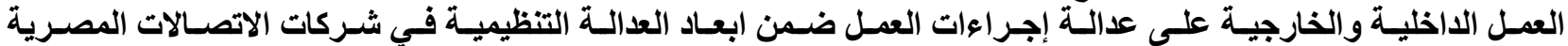
كما يلى: 


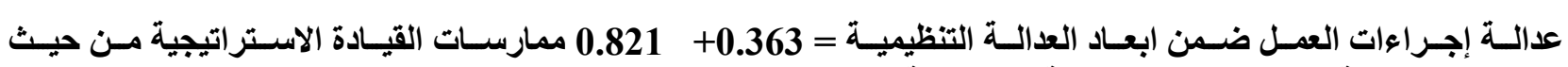
سلوك تفحص بيئة متغيرات العمل الداخلية والخارجية

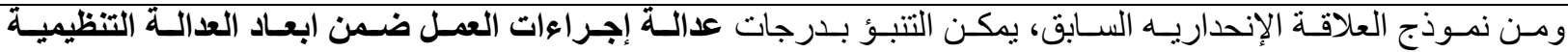

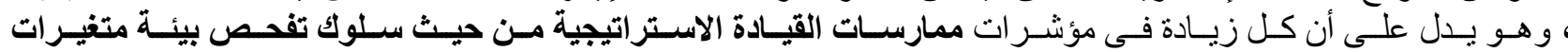

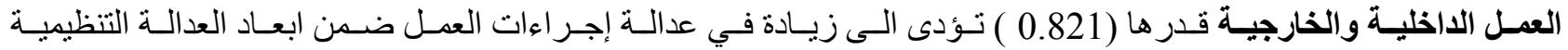

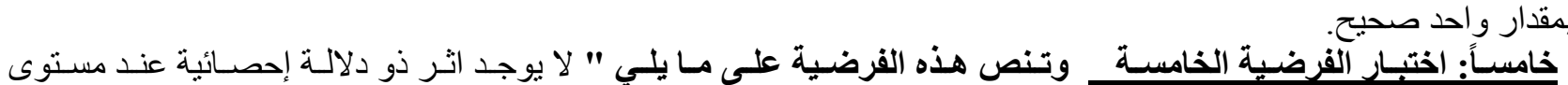

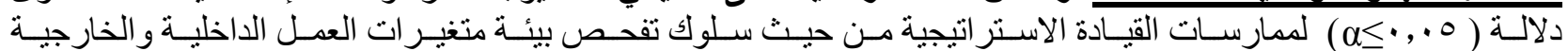

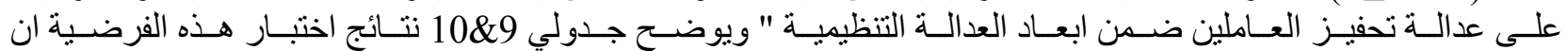

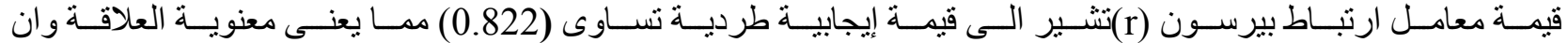

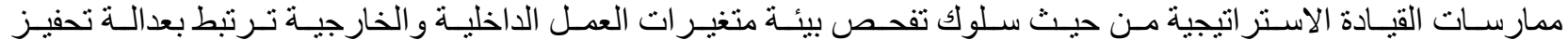

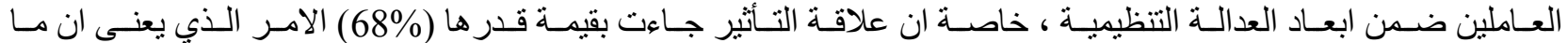

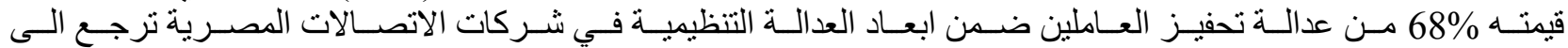

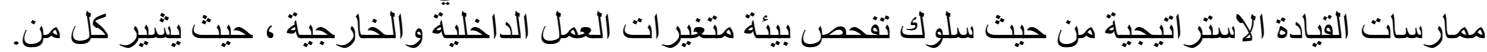

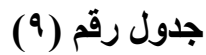

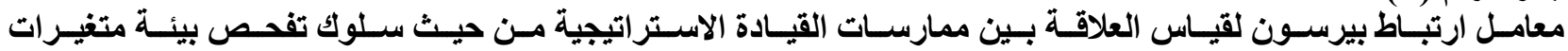

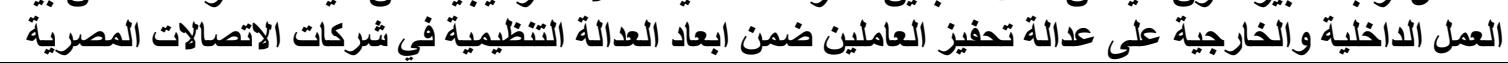

\begin{tabular}{|c|c|c|c|}
\hline (النتيجة) & 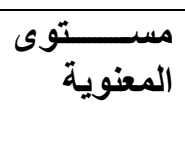 & 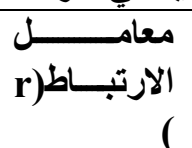 & العلاقة \\
\hline دالة & $* * 0.004$ & $* * 0.822$ & 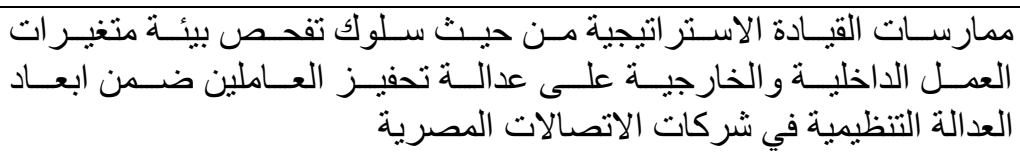 \\
\hline
\end{tabular}

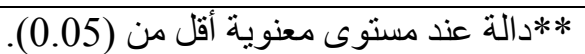

جدول رقم (10)

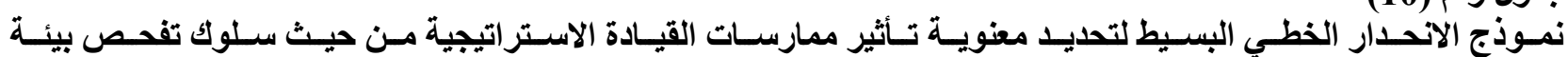

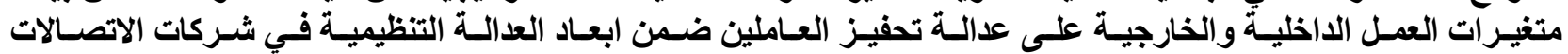
المصرية

\begin{tabular}{|c|c|c|c|c|c|c|}
\hline \multirow{2}{*}{$\begin{array}{r}\text { التحديل } \\
\text { R2 } \\
\text { R2 }\end{array}$} & \multicolumn{2}{|r|}{$\begin{array}{l}\text { قيمة "في } \\
\text { F. test }\end{array}$} & \multicolumn{2}{|r|}{$\begin{array}{l}\text { قيمة "ت } \\
\text { t. test }\end{array}$} & \multirow{2}{*}{$\begin{array}{r}\text { المقلمات } \\
\beta_{i}\end{array}$} & \multirow[t]{2}{*}{ لمتغير المستقل } \\
\hline & المعنوية مستوى & القيمة & المعنوية & القيمة & & \\
\hline \multirow[t]{2}{*}{$68 \%$} & $* * 0.004$ & 418.266 & $* * 0.004$ & 2.890 & 0.395 & 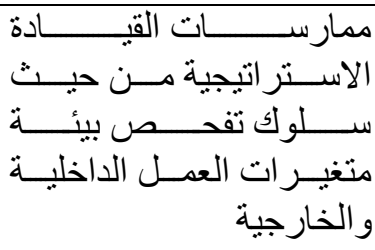 \\
\hline & & & $* * 0.004$ & 20.233 & 0.845 & \\
\hline
\end{tabular}

(0.05). 


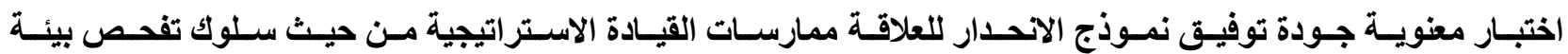

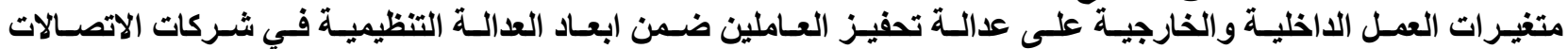

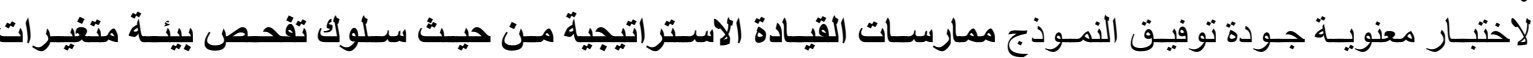

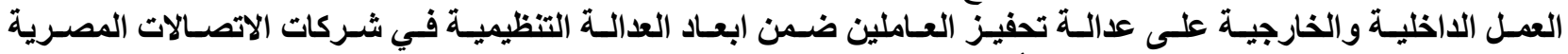

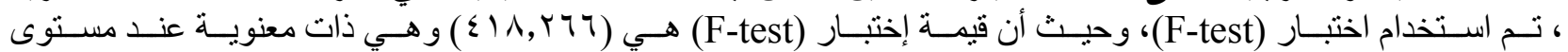

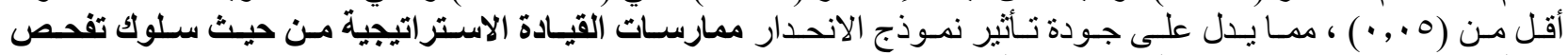

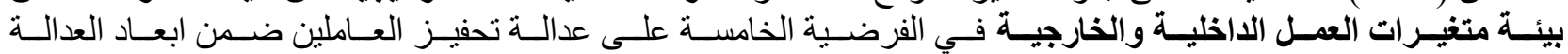

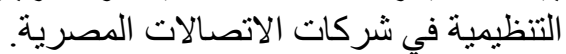

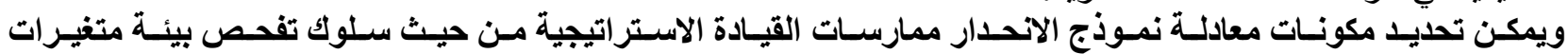

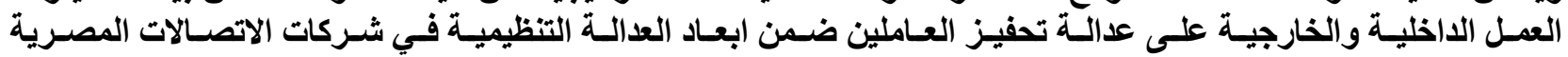
كما يلى:

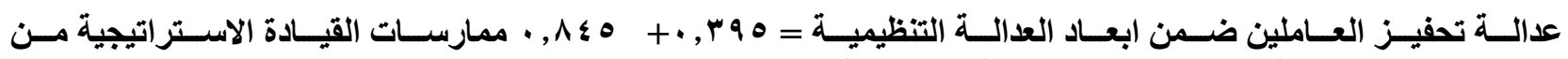
حيث سلوك تفحص بيئة متغيرات العمل الداخلية والخارجية

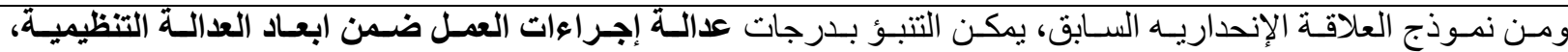

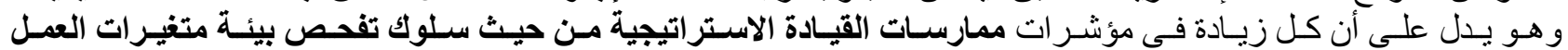

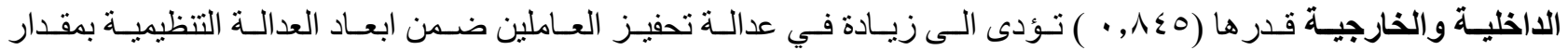

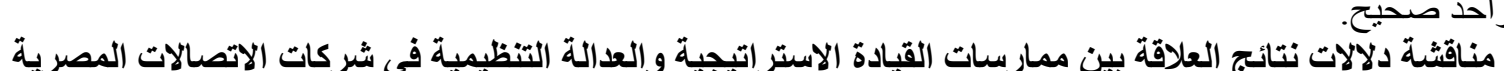

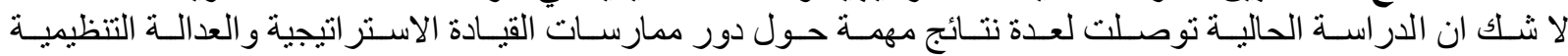

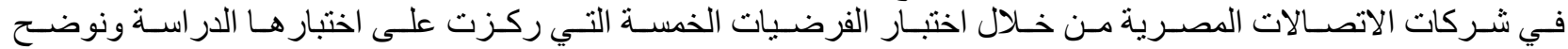

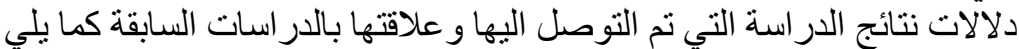

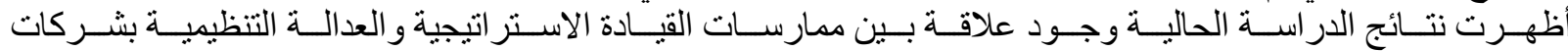

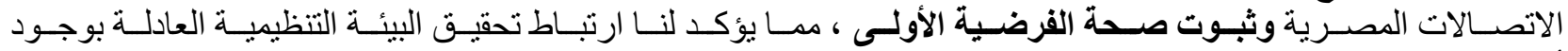

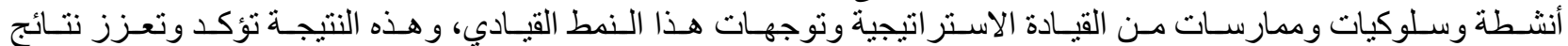

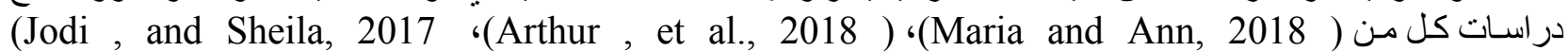

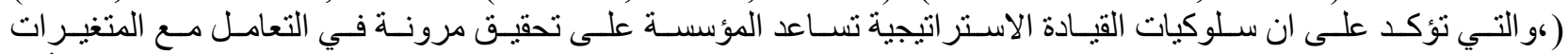

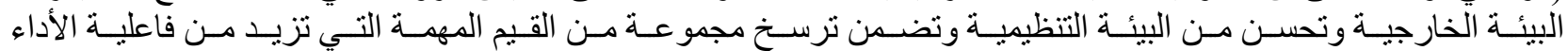

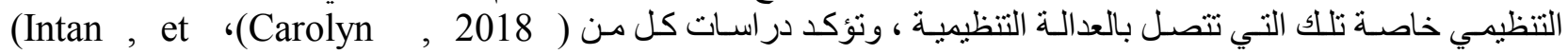

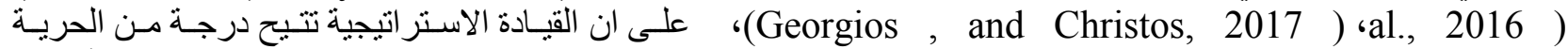

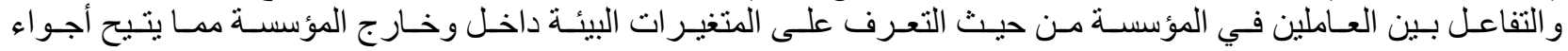

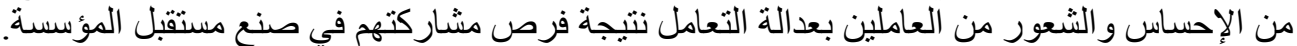

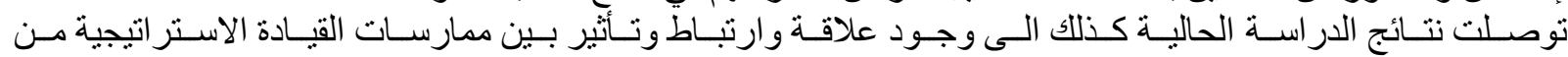

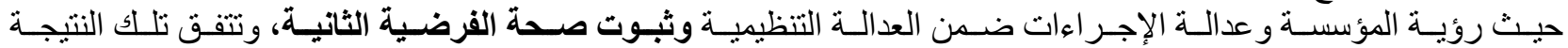

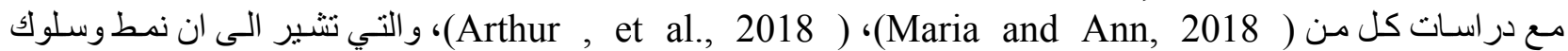

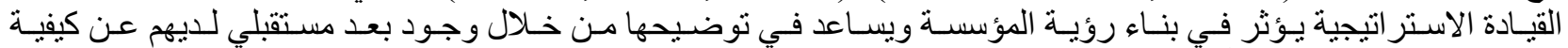

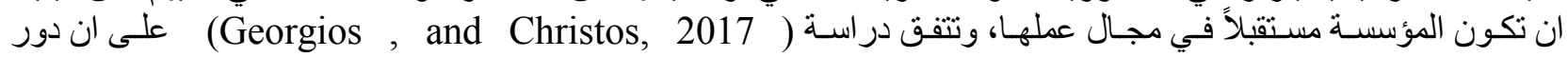

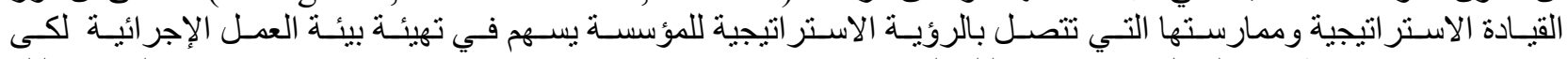

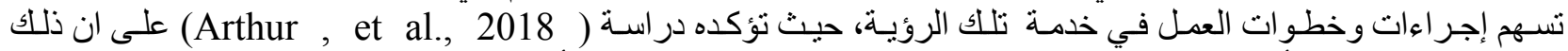

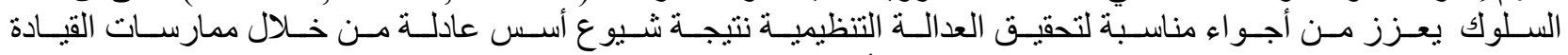
الاستر اتيجية وسلوكها تجاه التشجيع على سهولة ومرونة أداء العمل المؤسسى لتحقئ التحقيق رؤية المؤسسة المستقبلية.

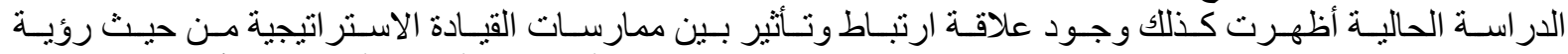

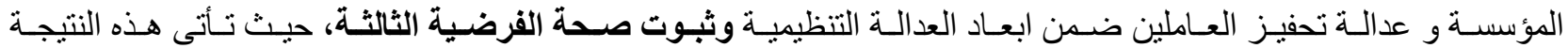

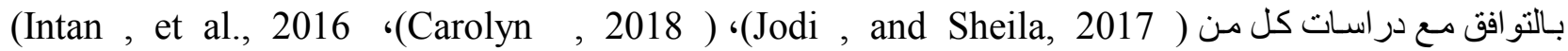

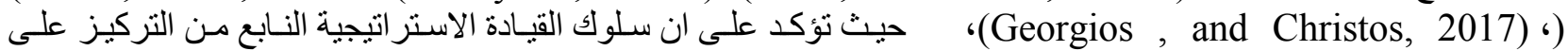

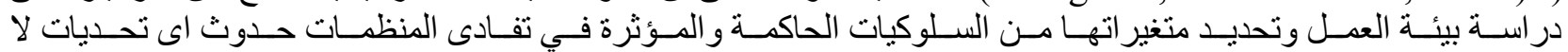

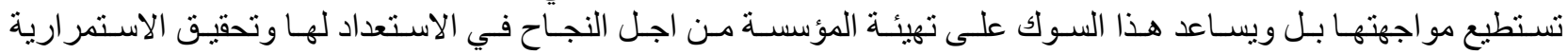




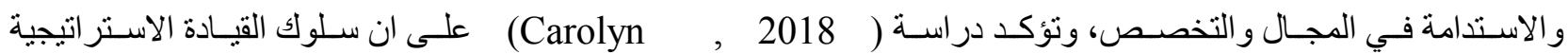



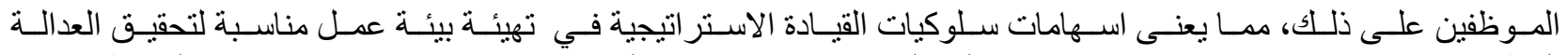

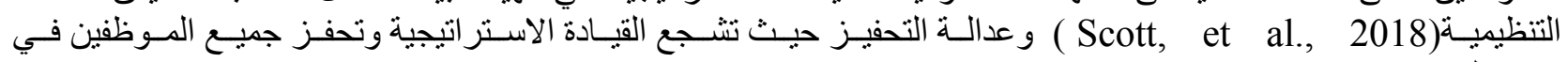
جميع المستويات بتحفيز هم) (Jodi , and Sheila, 2017).

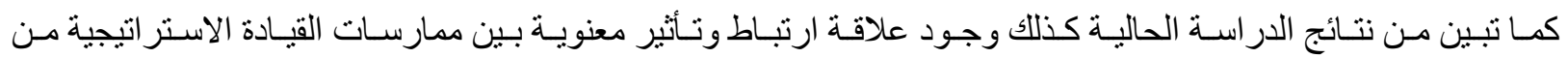

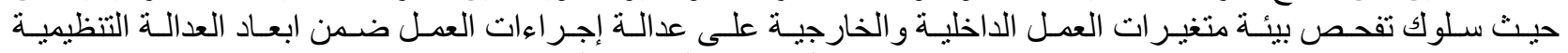

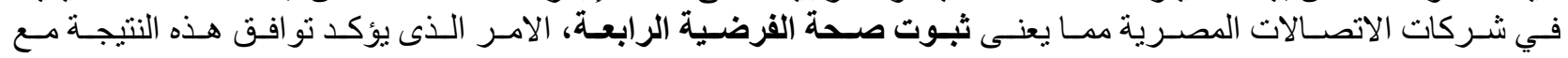

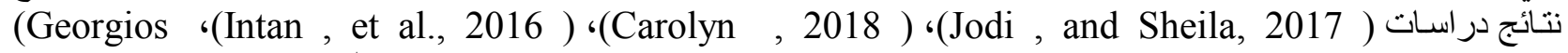

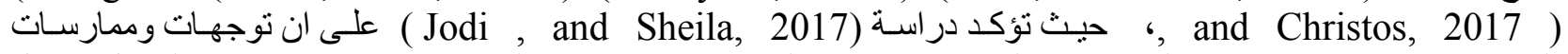

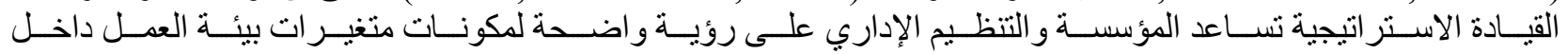

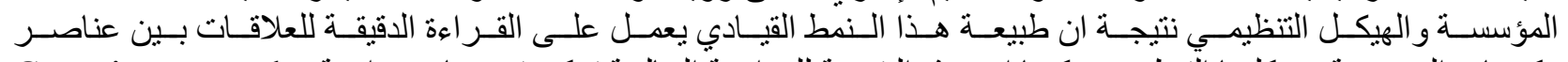

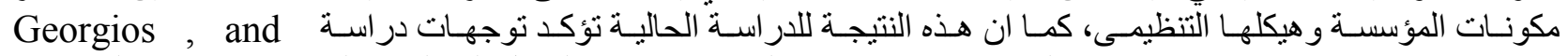

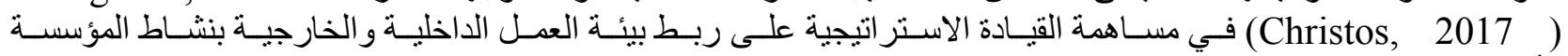

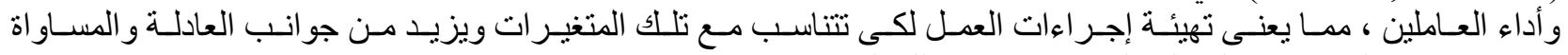

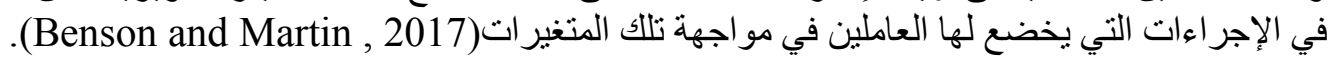

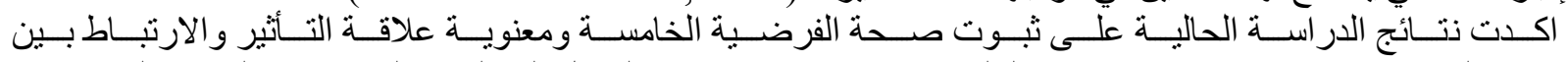

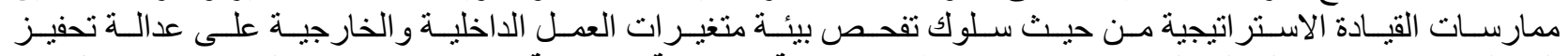

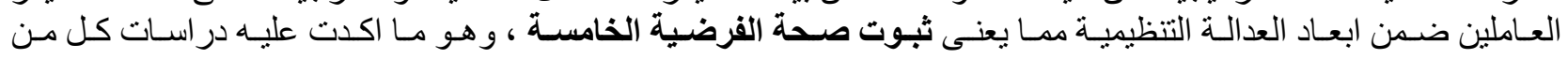
(Benson and ‘(Scott, et al., 2018 ) ،(Raphael, et al., 2018 ) ‘(Benson and Martin , 2017 ) ‘(Intan , et al., 2016 ) (Carolyn , 2018 ) ‘(Jodi , and Sheila, 2017 ) ‘Martin , 2017 )

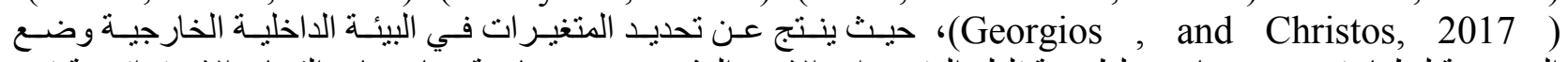

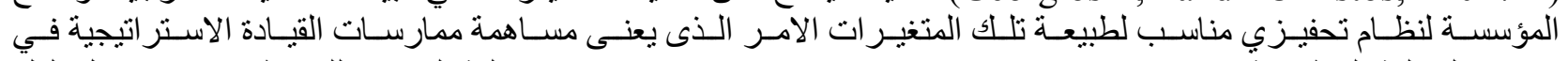

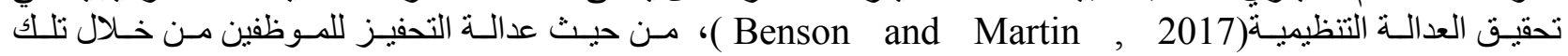

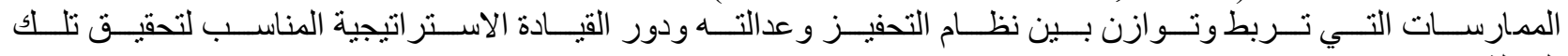

العدالة( Benson and Martin , 2017).

\section{مقترحات وتوصيات الدراسة}

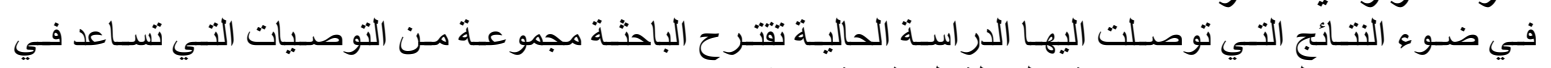

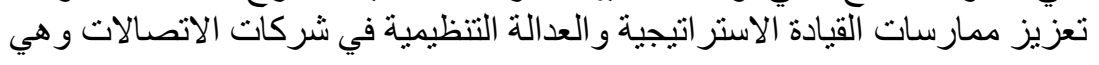

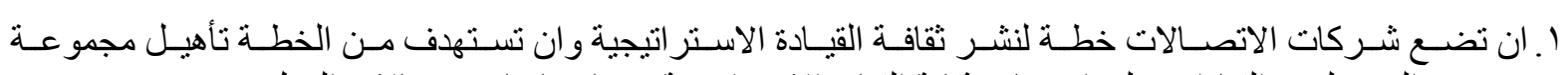

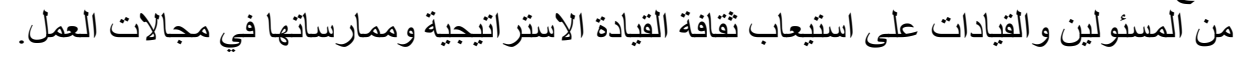

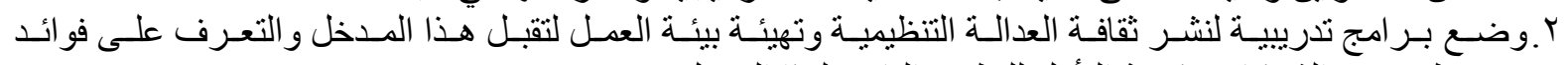

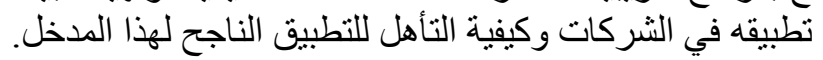

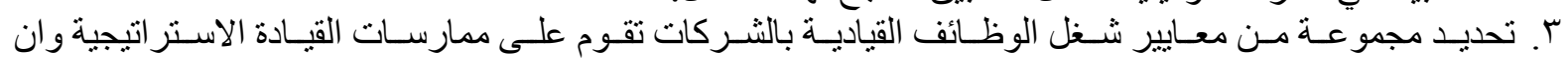

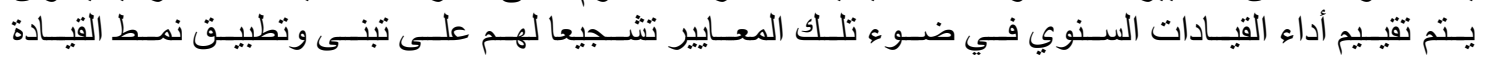
الاستر اتيجية.

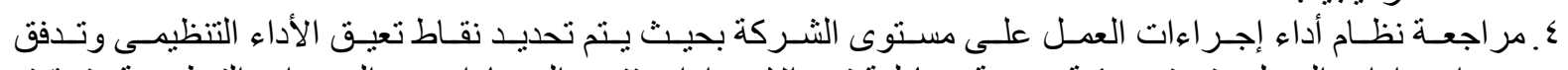

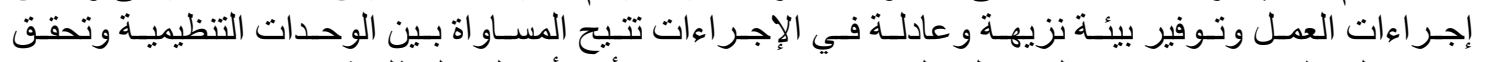

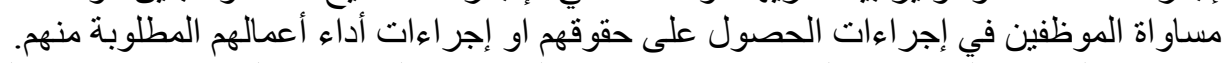

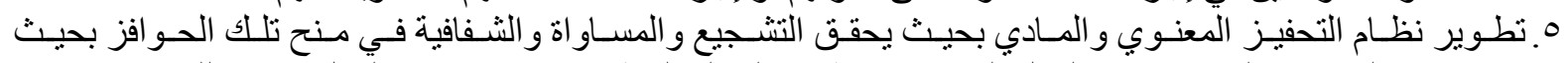

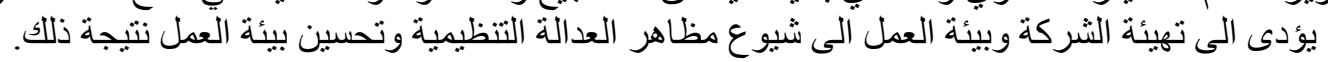

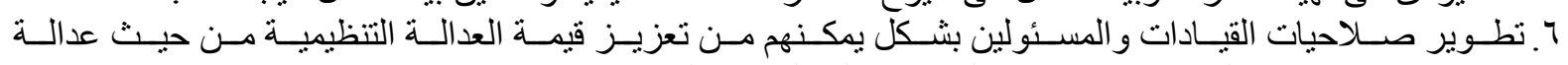
الإجر اءات ومسئوليتهم عن تحقيق عدالة تحفيز العاملين في الثركات.

\section{التوجهات البحثية المستقبلية}

تقترح الباحثة اجر اء المزيد من البحوث المستقبلية في الموضو عات الاتية 


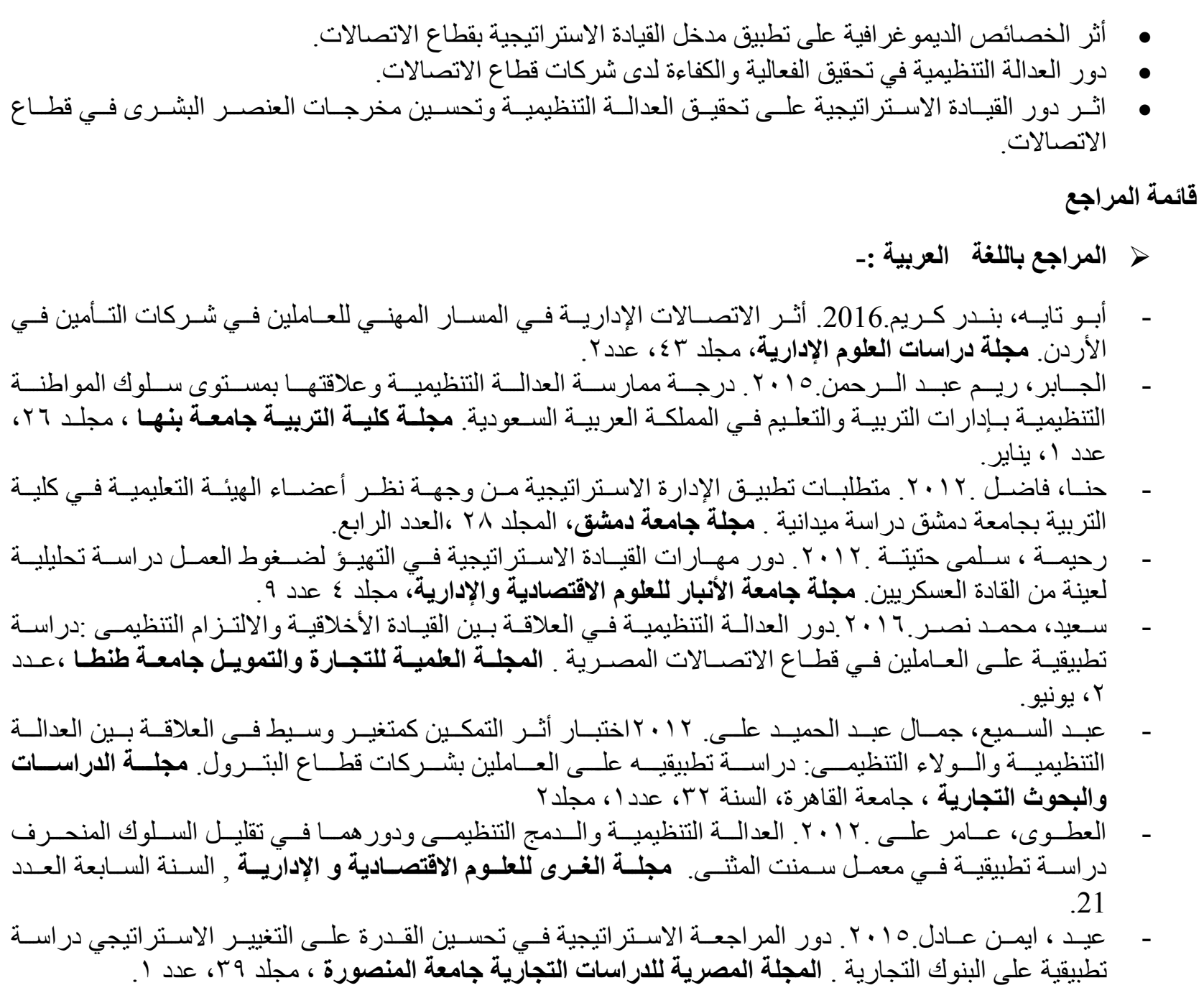

\section{المراجع باللغة الإنجليزية}

- Ahmed M. E., Mohamed Y. H.2017.The role of wisdom leadership in increasing job performance: Evidence from the Egyptian tourism sector. Tourism Management, V. 63, December pp: 66-76.

- Amber M. A., Jennifer B. C.2016.Functional leadership: Bi-strategic controllers high on effortful control show gains in status and health. Personality and Individual Differences, V.97, July pp: 193-197.

- Arthur R., Gerald A. S., Bryan S. S., Joseph S. L.2018.Self-awareness and leadership: Developing an individual strategic professional development plan in an MBA leadership course. The International Journal of Management Education, V. 16, 1, March pp: 1-13.

- Benson T. H. Lim\& Martin Loosemore.2017.The effect of inter-organizational justice perceptions on organizational citizenship behaviors in construction projects. International Journal of Project Management, V. 35, 2, February pp: 95-106.

- Carolyn S. H.2018.Inside a Strategic Plan for a Dysfunctional Senior Leadership Team. Nurse Leader, V. 16, 2, April pp: 142-146.

- Cindy P. Z., Jesse E. O., Luis L. M .2013.Social exchange from the supervisor's perspective: Employee trustworthiness as a predictor of interpersonal and 
informational justice. Organizational Behavior and Human Decision Processes, V.121, 1, May pp: 1-12.

- Elizabeth C. K., Barry A. C., Florian L. F., Antony U., Bob W.2017.Relational leadership for strategic sustainability: practices and capabilities to advance the design and assessment of sustainable business models. Journal of Cleaner Production, V. 140, Part 1, 1 January pp: 189-204.

- Georges D., Michelle D.2017.Strategic leadership for sustainability by higher education: the American College \& University Presidents' Climate Commitment. Journal of Cleaner Production, V. 140, Part 1, 1 January pp: 111-116.

- Georgios C. \& Christos M.2017.Strategic fiscal policies and leadership in a monetary union. European Journal of Political Economy, V. 47, March pp: 133-147.

- Intan M. A. R., Irza H. A. S., Razleena R., Muhammad F. S., Mohd K.Z.2016.The Importance of Perceived Leadership Elements in Strategic Planning at Public University. Procedia Economics and Finance, V.39, pp: 422426.

- Jaclyn A. M., Jonathan C. Z.2016.Vertical flow of collectivistic leadership: An examination of the cascade of visionary leadership across levels. The Leadership Quarterly, V. 27, 2, April pp: 334-348.

- Jeff Shockley, Tobin Turner.2016.A relational performance model for developing innovation and long-term orientation in retail franchise organizations. Journal of Retailing and Consumer Services, V. 32, September pp: 175-18.

- Jodi D.\& Sheila S. W.2017.Strategic shifts that build executive leadership. Business Horizons, V. 60, 3, May-June, pp: 335-343.

- Joel K., Fadel K. M., Brent A. S., Donald E. C.2015.Ingratiation and popularity as antecedents of justice: A social exchange and social capital perspective. Organizational Behavior and Human Decision Processes, V. 131, November pp: 132-148.

- Juliana D. Lilly .2017. What happened to civility? Understanding rude behavior through the lens of organizational justice. Business Horizons, V.60, 5, September-October pp:707-714.

- Kelly J. Fadel, Alexandra Durcikova.2014. If it's fair, I'll share: The effect of perceived knowledge validation justice on contributions to an organizational knowledge repository. Information \& Management, V. 51, 5, July pp: 511-519.

- Lale G., Zahide K. A., Giles H.2013. Transformational leadership and R\&D workers' multiple commitments: Do justice and span of control matter? Journal of Business Research, V. 66, 11, November 2013, pp: 2269-2278.

- Lesley F., David S., Ian O.2018.Leadership in governance: Exploring collective board leadership in sport governance systems. Sport Management Review, V. 21, 3, June pp: 221-231.

- Maria L.\& Ann L.2018. The social construction of strategic coherence: Practices of enabling leadership. Long Range Planning, 24 May .

- Mohammad N. K., Mohammad B. K., Tasneem F., Syed Z.A.S.2018.The underlying mechanism between perceived organizational injustice and deviant workplace behaviors: Moderating role of personality traits. Asia Pacific Management Review 26 May .

- Raphael M. H., Jos A. B., Adrian L., Bernd G., Joachim E. F.2018.Organizational justice, justice climate, and somatic complaints: A multilevel investigation. Journal of Psychosomatic Research, V.111, August pp: 15-21. 
- Satu K., Jukka L., Michael J. P.2013. Organizational and supervisory justice effects on experienced threat during change: The moderating role of leader ingroup representativeness. The Leadership Quarterly, V.24, 4, August pp: 595607.

- Scott E. W.e., Jeff R., Victor M. M. ,Allison R.2018. Why does organizational justice matter? Uncertainty management among law enforcement officers. Journal of Criminal Justice, V. 54, January-February pp: 20-29.

- Syeda A. Z. K., Marja N., Juha K. W.2016.Integrating Strategic Thinking and Transformational Leadership for NPD Idea Support Process. Social and Behavioral Sciences, V. 229, 19 August pp: 387-397.

- Tayyaba A., Shen L.i., Muhammad J. H., Syed T. C., Mustelier P., HussainL.2017.The effect of organizational justice on knowledge sharing: Empirical evidence from the Chinese telecommunications sector. Journal of Innovation \& Knowledge, V. 2, 3, September-December pp: 134-145.

- Xiaoshan L., Jianxin Z., Shanshan Z., Mingjie Z.2017.A multilevel analysis of the role of interactional justice in promoting knowledge-sharing behavior: The mediated role of organizational commitment. Industrial Marketing Management, V. 62, April pp: 226-233.

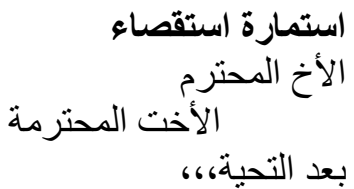

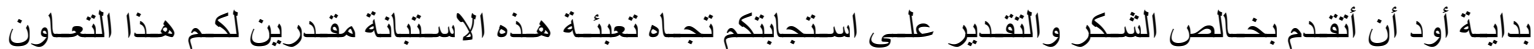

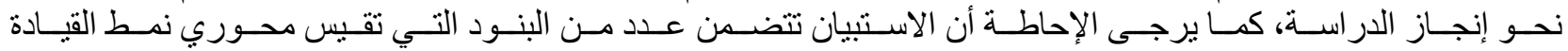
الاستر اتيجية و العدالة التنظيمية.

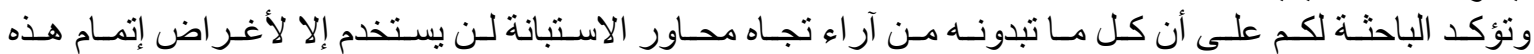
الدر اسة و البحث العلمي فقط. مع خالص تقليري،

اولاً: فيمـا يلـي مجموعـة مـن المقـاييس الخاصـة بممارســات القيـادة الاسـتراتيجية رجـاء إبــاءع الـرأي بمـا يتوافق مـع وجهة نظركم:

\begin{tabular}{|c|c|c|c|c|c|c|}
\hline 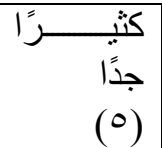 & $\begin{array}{l}\text { كثيرًا } \\
\text { (ع) }\end{array}$ & $\begin{array}{c}\text { وسط } \\
\text { (r) }\end{array}$ & قليلاً & قدًاً & 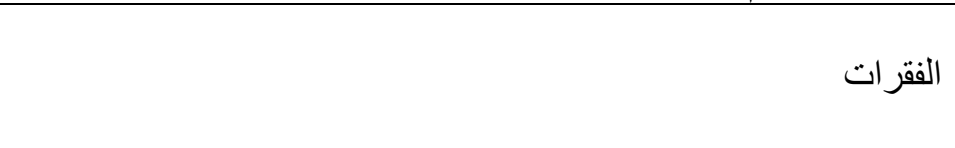 & r \\
\hline & & & & & أشجع وجود اتصالات و اضحة لتدفق المعلومات و أنظمة المر اقبة. & 1 \\
\hline & & & & & أعمل على تشجيع الموظفين لإنجاز المهام المطلوبة منهم. & Y \\
\hline & & & & & أميل إلى العمل كفريق متعاون مع الموظفين. & 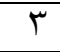 \\
\hline & & & & & تقوم الإدارة بتوفير الحو افز المعنوية والمادية المناسبة. & $\varepsilon$ \\
\hline & & & & & أقوم بتهيئة الأجو اء المناسبة لبيئة العمل. & 0 \\
\hline & & & & & أحرص على إيجاد آلية مثمرة لتطوير العمل. & 7 \\
\hline & & & & & لدى قناعة بتحديد رؤية مستقبلية للعمل بالمنظمة. & $\mathrm{V}$ \\
\hline & & & & & 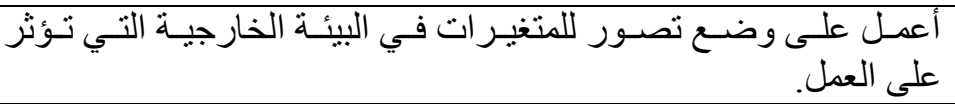 & $\wedge$ \\
\hline & & & & & أهتم كثيرًا ببناء الثقة بين الموظفين التابعين لي. & 9 \\
\hline & & & & & 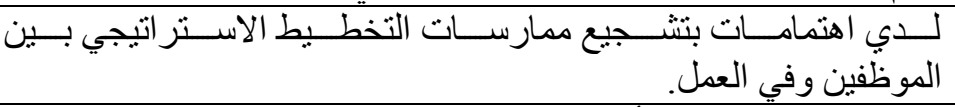 & $1 \cdot$ \\
\hline & & & & & الإبداع في العمل شيء أساسي وضروري بالنسبة لي. & 11 \\
\hline & & & & & أتقبل أَفكار ومقترحات و آراء الآخرين البناءة. & IT \\
\hline
\end{tabular}




\begin{tabular}{|c|c|c|c|c|c|c|}
\hline كثًا & 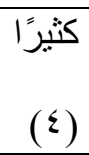 & وسط & قليلاً & قدًاً & 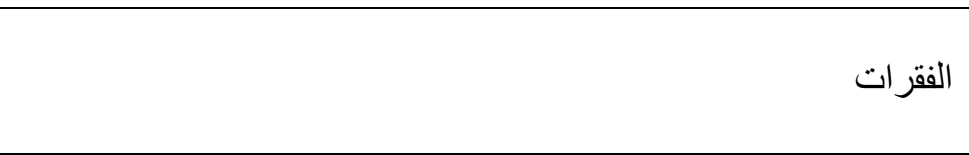 & ? \\
\hline & & & & & أحرص على وجود علاقات اجتماعية بين جميع العاملين. & 14 \\
\hline & & & & & أهتم بتطوير إجر اءات وخطوات العمل وفق المستجدات البيئية. & $1 \leq$ \\
\hline & & & & & لدى القناعة و الثقة بأننا سنحقق ما نطمح إليه مستقبلاً. & 10 \\
\hline & & & & & أميل إلى وجود مرونة في تيسير إجر اءات وأنشطة العمل. & 17 \\
\hline & & & & & 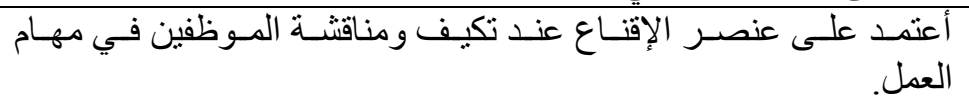 & IV \\
\hline & & & & & 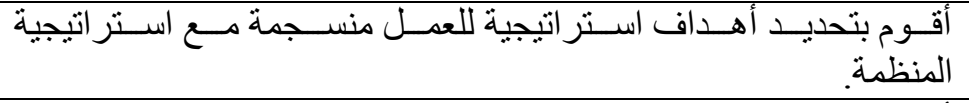 & 11 \\
\hline & & & & & 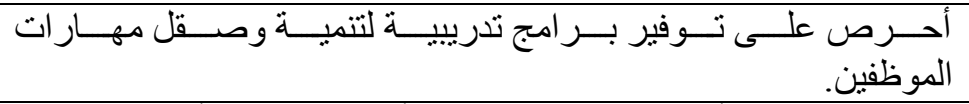 & 19 \\
\hline & & & & & اعمل على وضع أهداف تشغيلية لتحقيق الأهداف طو يلة الأجل. & $r$. \\
\hline
\end{tabular}

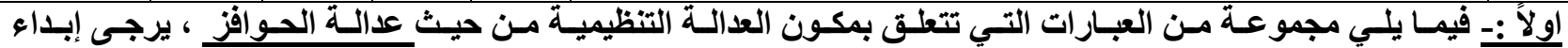

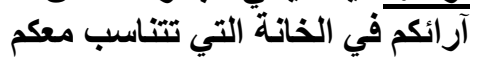

\begin{tabular}{|c|c|c|c|c|c|c|}
\hline تماماً & موافق & محايد & موافق & 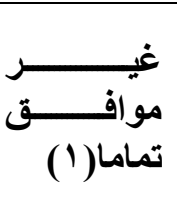 & الفقرات & p \\
\hline & & & & & يوجد نظام عادل للمكافآت و الحو افز المادية & 1 \\
\hline & & & & & واضلــنة الثـــركة عــن أســس مــنح العــلاو ات بصـــورة & $r$ \\
\hline & & & & & 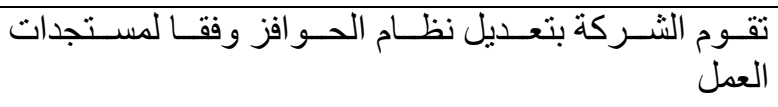 & $r$ \\
\hline & & & & & 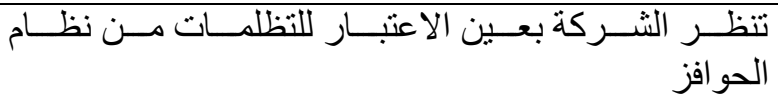 & $\varepsilon$ \\
\hline & & & & & 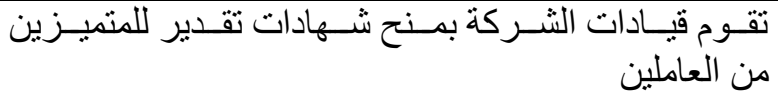 & 0 \\
\hline & & & & & تضع الثركة قيم مالية عادلة لجهود العاملين & 7 \\
\hline & & & & & 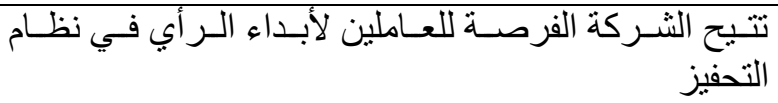 & $\mathrm{V}$ \\
\hline & & & & & التحفيز بالوز مسـتورةت مرتفعـة مـن رضــات العـاملين عـن نظــام & $\Lambda$ \\
\hline & & & & & تستتد قرار ات الترقيات الى أسس مالية عادلة & 9 \\
\hline & & & & & 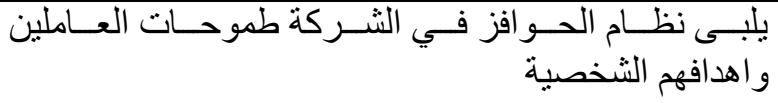 & 1. \\
\hline
\end{tabular}

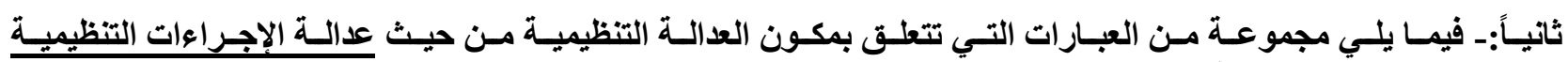

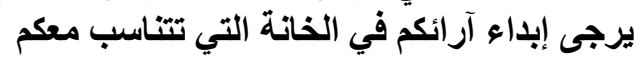




\begin{tabular}{|c|c|c|c|c|c|c|}
\hline تماماً & موافق & محايل & غوافق & 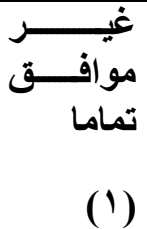 & الفقرات & p \\
\hline & & & & & توفر الثركة للعاملين إجر اءات عمل ميسرة وو اضحة & 1 \\
\hline & & & & & يتم اتحاذ القرار ات في ضو عشاركة العاملين فيها & r \\
\hline & & & & & 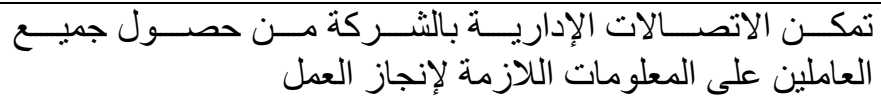 & $r$ \\
\hline & & & & & 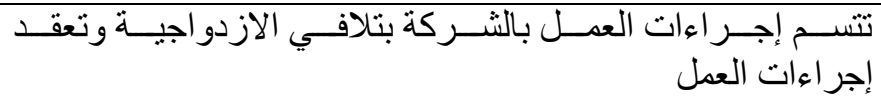 & $\varepsilon$ \\
\hline & & & & & 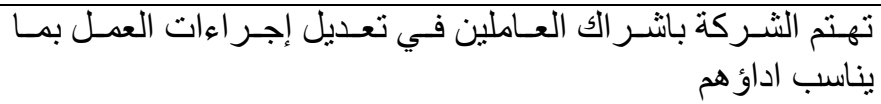 & 0 \\
\hline & & & & & هناك تتاسب للاهيكل التنظيمى مع إجر اءات العمل & 9 \\
\hline & & & & & 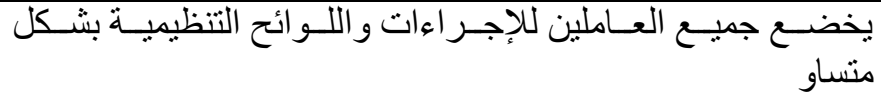 & $\mathrm{v}$ \\
\hline & & & & & 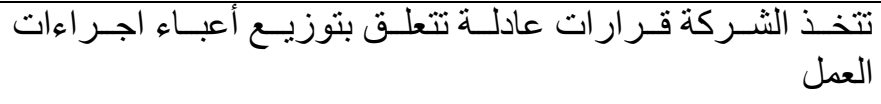 & $\wedge$ \\
\hline & & & & & تضع الشركة إجر اءات عادلة لتقييم الأداء الوظيفى للعاملين & 9 \\
\hline
\end{tabular}

